\title{
EL LARGO OCASO DEL CAMPO COMÚN. DIVISIÓN DE CONDOMINIOS Y EXPLOTACIÓN FORESTAL EN SANTIAGO DEL ESTERO (ARGENTINA), 1890-1918. ${ }^{1}$
}

\author{
Judith Farberman \\ CEHCME-UNQ /UBA/CONICET \\ (Buenos Aires, Argentina) \\ ORCID: https://orcid.org/0000-0003-4273-9009 \\ jfarberman@gmail.com
}

En el interior argentino alcanzaron cierta difusión durante la colonia y el siglo XIX los llamados «campos comunes», propiedades colectivas de carácter indiviso. Luego de la sanción del Código Civil en 1871, estas formaciones fueron asimiladas al condominio, con la expectativa de su pronta disolución. El artículo se ocupa del dificultoso proceso de división de condominios en una zona de Santiago del Estero - al noroeste del río Dulce- a fines del siglo XIX y principios del XX. Nuestra hipótesis es que, tanto la división del condominio de Los Gallardos —ejemplo sobre el que se profundiza-, como de otros de aquella región, resultó de la reconversión productiva del comunal por excelencia: el monte. Aunque la zona analizada se encontraba distante de la que fuera epicentro del obraje forestal, la valorización de la madera y de la leña estimuló a especuladores externos y también a algunos condóminos a exigir la división de sus estancias.

Palabras clave: Propiedad colectiva - Condominio - Montes comunes - Santiago del Estero

\section{THE SLOW DOWNFALL OF THE COMMONS. DIVISION OF CONDOMINIA AND FORESTRY IN- DUSTRY IN SANTIAGo DEL ESTERo (ARGENTINA), 1890-1918}

In the Argentine inland areas, from the colonial period to the 19 th century, the so-called «common lands» -indivisible collective properties — gathered considerable prominence.

1. En 1992, cuando me encontraba en plena búsqueda de fuentes para mi investigación doctoral, le comenté a Juan Carlos sobre el hallazgo de un documento en el que se hablaba del poseer «en mancomún». Me aconsejó entonces que siguiera el tema, que allí había algo importante. Aunque en la tesis lo consideré, no pude profundizar la cuestión hasta hace unos pocos años. Creo que estas páginas le habrían gustado porque parten de sus inquietudes y sus preguntas.

[Recibido: 23/4/19; Aceptado: 4/6/19] 
After the Civil Code sanction in 1871, these undivided lands were assimilated into the condominium, leading to the expectation of their dissolution. This article focuses on the problematic division process of condominiums in the Santiago del Estero province, northwest of Rio Dulce, towards the end of the 19th century and the beginning of the 20th. It is our bypothesis that, in the condominium division of Los Gallardos - a case that the article specifically delves into- as in others in the same region, turned into the most common type of productive communal reclaiming: the woods. Even though the analysed area was to be found far away from the epicenter of forestry industry, the appreciation of its resources led to external speculators, and also some condominos, to demand the division of their estates.

KEYWORDS: Colective property - condominium - common woods - Santiago del Estero province.

\section{Introducción}

Hacia fines del siglo XIX, una oleada de juicios de división procuró con éxito dispar la liquidación de numerosos condominios santiagueños situados en diferentes departamentos del río Dulce. Este fenómeno es ilustrativo tanto de la transición de formas antiguas de dominio hacia otras nuevas, como de los obstáculos que ésta debía sortear para ser llevada a la práctica. La figura jurídica del condominio — que pertenecía al código civil de 1871 y había sido «concebida para morir»— pretendía, en efecto, abarcar perdurables y diversas formas colectivas de poseer - como el pueblo de indios o el campo comunero- ampliamente difundidas en determinadas zonas el territorio argentino. ${ }^{2}$

Los pueblos de indios santiagueños habían sido disueltos poco después de las revoluciones de independencia en un proceso en apariencia poco conflictivo. En contraste, algunos «campos comuneros» han llegado hasta nuestros días en ciertas regiones de la provincia y en otras del interior argentino y su extinción enfrentó enconadas resistencias. ${ }^{3}$ De estas propiedades indivisas surgidas de las mismas prácticas y costumbres de

2. Cf. Cacciavillani, Pamela y Judith Farberman, «Nacido para morir: reflexiones en torno al uso del término condominio en el contexto de los campos comunes», inédito, 2019.

3. Ya existen varios trabajos sobre campos comunes para diversas provincias del noroeste argentino. Sin pretensiones de exhaustividad, destacamos los de Tell, Sonia, «Campos en común, campos contendidos. Apropiaciones de la comunidad en Córdoba (siglo XIX)», Revista de Ciencias Sociales, núm. 27, Bernal, 2015, pp. 6785; Teruel, Ana y Cecilia Fandos, «Procesos de privatización y desarticulación de tierras indígenas en el norte de Argentina en el siglo XIX», Revista Complutense de Historia de América, núm. 35, Madrid, 2009, pp. 233-256; López, Cristina, «Tierras comunales, tierras fiscales: el tránsito del orden colonial a la revolución», Revista Andina, núm. 43, Cuzco, 2006, pp. 215-238 y Boixadós Roxana y Judith Farberman, El país indiviso. Poblamiento, conflictos por la tierra y mestizajes en Los Llanos de La Rioja durante la colonia, Buenos Aires, Prometeo, en prensa. Ver también los estudios etnográficos sobre Catamarca de Bernarda Zubricki, entre ellos «Herederos dueños y "derechosos". Propiedad y herencia de la tierra en Asampay, Argentina», Sociedades Rurales, Producción y Medio Ambiente, núm. 4, vol. 1, México, 2003, pp. 19-27. 
los sujetos rurales, nos hemos ocupado por extenso en trabajos anteriores, por lo que nos limitaremos a sintetizar brevemente algunos rasgos que las definían. ${ }^{4}$

En primer lugar, su consistencia con un tipo de producción, entorno ambiental y condiciones históricas, además de la evidente conveniencia de ahorrarles a los dueños los ingentes gastos de los trámites sucesorios. A lo largo del río Dulce y durante siglos, las familias santiagueñas habían creado una verdadera ingeniería de supervivencia que combinaba la agricultura de bañados, la recolección de frutos silvestres, la ganadería a monte en pequeña escala, la textilería doméstica y la migración estacional. ${ }^{5}$ La asociación de estas diversas actividades casaba muy bien con el manejo colectivo del agua y de los recursos del monte, que alternaba con la posesión individual de rastrojos y haciendas.

En segundo lugar, los campos comunes se fundaban sobre el parentesco. Esta afirmación, que puede parecer banal para el momento de origen de las estancias indivisas, no lo es tanto si se considera el devenir más que centenario de algunas de ellas. Entendemos que el parentesco fijaba los confines de la membresía y también las jerarquías entre los compartes: sin dudas, la descendencia directa del «tronco principal» y la legitimidad de nacimiento contaban en la peculiar estratificación del campo común. Sin embargo, aunque la memoria genealógica de algunos condóminos fuera profunda y minuciosa, los vínculos de parentesco se volvían más confusos en la medida en que la población se multiplicaba, favoreciendo imposturas y creando un clima de recíproca desconfianza. Era de los «troncos principales» que salían los llamados «tutores» o «autores» de la comunidad, a menudo mujeres, que representaban a los compartes en los pleitos civiles y que quizás también coordinaran la gestión de los recursos y la organización de ciertos trabajos comunitarios.

En tercer lugar, junto a los «dueños» —que recibían sus derechos de propiedad por vía materna, paterna o ambas — circulaban los «agregados». Un «dueño» dudoso podía resbalar fácilmente en «agregado», de quien se esperaba la entrega de una renta en trabajo a cambio del acceso a tierras. ${ }^{6}$ El campo comunero, por tanto, no era una comunidad

4. Farberman, Judith «Los avatares de la mancomunión. Propiedad indivisa, armonías y conflictos en las costas del río Dulce. Santiago del Estero, siglos XVIII y XIX», Revista de Indias, núm. 275, vol. 4, Sevilla, 2019, pp. 111-142; «Dueños, agregados, derechos de propiedad y matrices comunales en Santiago del Estero. Una aproximación histórica». Cf. Paz, Raúl; Ramiro Rodriguez Sperat y Cristian Jara (coords.), Sistemas comunales, estructura agraria y explotaciones agropecuarias sin límites definidos: miradas alternativas, dilemas y disyuntivas, Santiago del Estero, EDIUNSE, 2018, pp. 63-106; «Tierras mancomunadas en Santiago del Estero. Problemas y estudios de caso entre la colonia y el siglo XIX», Mundo Agrario, vol. 17, núm. 36, La Plata, 2016. Disponible en: <http://www.mundoagrario.unlp.edu.ar/article/view/MAe025>; «El mancomún en Santiago del Estero entre la colonia y el siglo XIX. Historia y fundamentos de un problema de investigación», Indoamérica, núm. 7, Santiago del Estero, 2016, pp. 13-36.

5. Palomeque, Silvia, «Los esteros de Santiago. Acceso a los recursos y participación mercantil, Santiago del Estero en la primera mitad del siglo XIX», Data. Revista del Instituto de Estudios Andinos y Amazónicos, núm. 2, La Paz, 1992, pp. 9-63; Farberman, Judith, «Familia, ciclo de vida y economía doméstica. El caso de Salavina, Santiago del Estero, en 1819», Boletín del Instituto Ravignani, núm. 12, Buenos Aires, 1996, pp. 33 59.

6. Nos ocupamos específicamente de la condición de los agregados en Farberman, Judith, «Dueños, agregados...», cit. 
de iguales, aunque hasta el pariente o agregado más pobre encontrara algún sitio donde instalarse y sembrar su rastrojo.

De esta brevísima reseña puede intuirse la multiplicidad de aristas que ofrece nuestro objeto de investigación. Ya que las estancias indivisas son pensables en el marco más amplio de una suerte de «matriz comunal» que excede las formas de poseer para teñir las relaciones sociales en su conjunto y que es visible aún en nuestros días. ${ }^{7}$ Su existencia misma y amplia difusión sugiere también una lectura — aún pendiente- que anude el análisis de la estructura agraria y de la movilización política durante el siglo XIX, restituyendo la horizontalidad de las relaciones sociales a una historiografía local quizás demasiado atenta a los lazos de patronazgo. ${ }^{8}$ Por fin, otra vía de exploración apunta al análisis de la transición entre formas antiguas y nuevas de dominio. Tal será la perspectiva de este artículo que, en ruptura con nuestras contribuciones anteriores, se adentra en la historia contemporánea de la provincia.

En efecto, nuestro corpus documental privilegiará materiales de fines del siglo XIX y principios del XX, recortando una zona particular del río Dulce incluida en el departamento de Jiménez Segundo (luego, y hasta hoy, La Banda).

Entendemos que buena parte de las estancias allí existentes aún se encontraban «indivisas y por partir» al doblar el siglo XIX y que tenían a sus espaldas un largo pasado de campo común. Sin embargo, no por eso se trataba de estructuras inmutables. Aunque algunos de los rasgos ya señalados para los campos comunes coloniales se mantuvieran -la presencia de agregados, la relevancia de los «dueños principales» y muy especialmente la base campesina y la explotación diversificada de los recursos- otros habían cambiado. Los «dueños»-ahora llamados condóminos— se habían multiplicado, existían administraciones formalizadas (así lo exigía el Código Civil de 1871) y, sobre todo, múltiples presiones, internas y externas, conspiraban contra la propiedad colectiva.

Las presiones internas apuntaban a la dinámica misma de las formas de transferencia de los derechos de propiedad que, en algún momento del siglo XIX, comenzaron a circular por herencia y operaciones de compra venta como «derechos y acciones». ${ }^{9}$ Se trataba

7. Paz, Raúl, «Estructura agraria, explotaciones sin límites definidos y matrices comunales: miradas alternativas, dilemas y disyuntivas» y los estudios recopilados por Paz, Raúl; Ramiro Rodríguez Sperat y Cristian Jara (coords), Sistemas comunales..., cit.

8. En este último sentido, la historiografía sobre Santiago del Estero, partiendo de las obras de Orestes Di Lullo, había insistido - a nuestro juicio con demasiado énfasis — en los vínculos verticales (patronazgo) como matriz de las relaciones sociales en la provincia. Aunque ignoramos si seguían en este punto a Di Lullo y sin negar su existencia, insisten a veces excesivamente en el patronazgo los trabajos de Vessuri y Tasso, bien que para fines del siglo XIX y Xx. Ver Di Lullo, Orestes, El bosque sin leyenda. Ensayo Económico Social. Santiago del Estero, Tipografía Arcuri Caro,1937; Vessuri, Hebe, Igualdad y jerarquía en Antajé, Buenos Aires, IDES-Al Margen, 2011; Tasso, Alberto Ferrocarril, quebracho y alfalfa. Un ciclo de agricultura capitalista en Santiago del Estero, 1870-1940, Córdoba, Alción Editora, 2007.

9. Se trata de un caso muy similar al de los condueñazgos mexicanos. De los estudios existentes, destacamos el de Pérez Castañeda, Juan Carlos, «Los condueñazgos en México. Siglo XIX», Signos Históricos, núm. 40, México, 2018. <http://signoshistoricos.izt.uam.mx/index.php/SH>, consulta 7.11.2018. Para la Argentina, ver Zubricki, Bernarda, «Herederos...», cit. 
de alícuotas ideales o cuotas parte de la estancia indivisa cuya transferencia no siempre quedaba asentada en escrituras públicas. Gracias a estas operaciones, algunos compartes acumularon derechos y acciones - generalmente compradas a sus parientes-, a la vez que miembros «extraños» fueron ingresando a la trama comunitaria. Por otra parte, el mismo sistema terminó generando cierta dispersión de derechos y acciones de los mismos sujetos en distintos campos comuneros: de esta suerte, siguiendo un camino alternativo, la fragmentación que se esperaba conjurar siguió manteniéndose como amenaza.

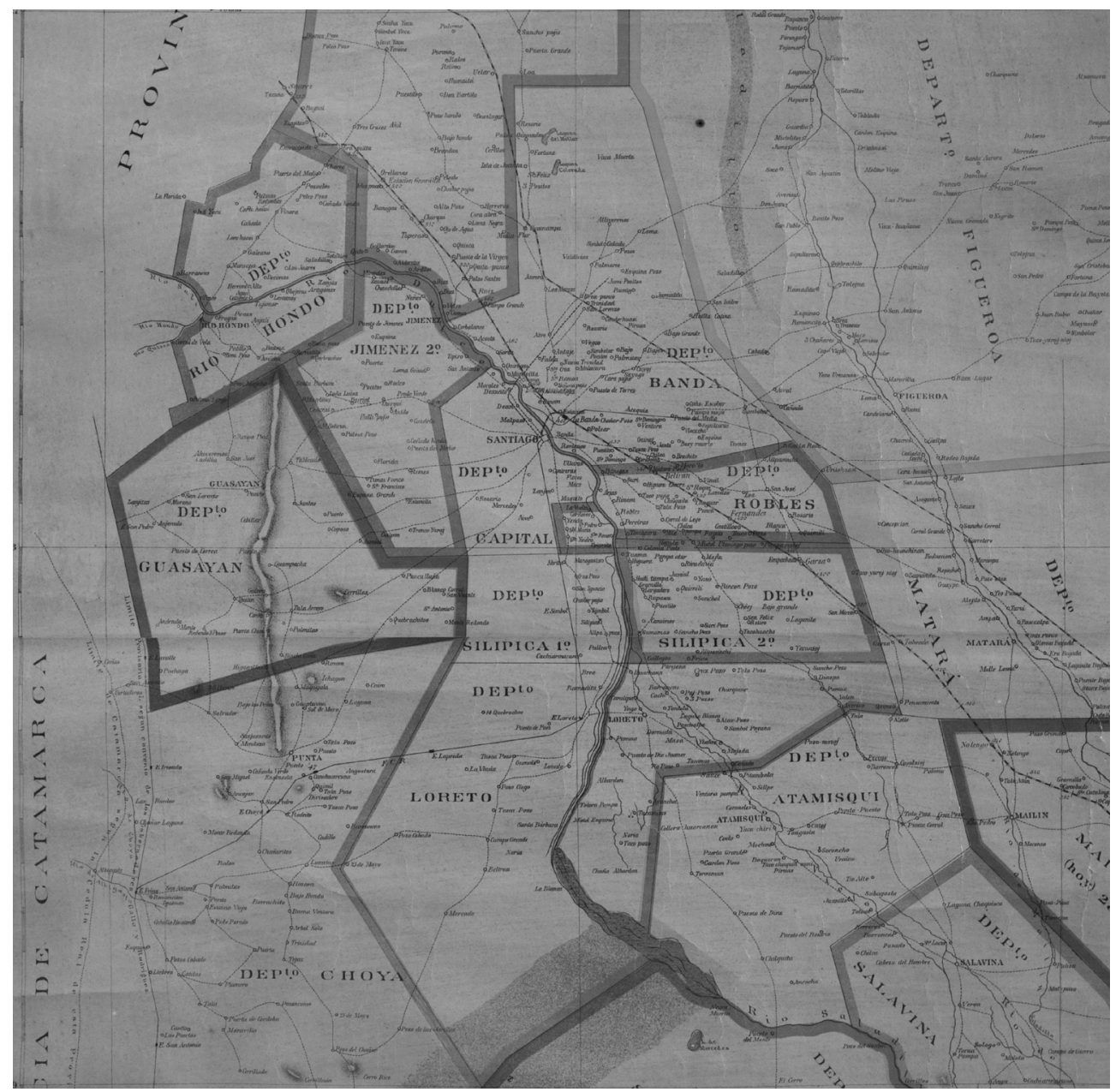

Sección del Mapa de la Provincia de Santiago del Estero de Guillermo Reid Buenos Aires: Lit. e Imp. G. Kraft [entre 1886 y 1889]. (Copia Biblioteca Nacional) 
Las presiones externas han de vincularse con los procesos simultáneos de consolidación del estado provincial y del desarrollo en Santiago del Estero del «ciclo de economía capitalista» fundado en la tríada alfalfa / obrajes / ferrocarriles. ${ }^{10}$ Quizás uno de los aspectos más estudiados de este proceso sea el de la veloz apropiación de tierras fiscales, sobre todo para la zona fronteriza con el Chaco. ${ }^{11}$ Nuestro caso, en cambio, se aparta de los mejor conocidos en dos sentidos, por lo menos. Por un lado, porque nos encontramos con tierras que por siglos habían pertenecido a arraigados y orgullosos colectivos de poseedores. Por el otro, porque el departamento de Jiménez Segundo no se hallaba ni mucho menos en la zona más dinámica de la provincia a fines del siglo XIX. Distante del epicentro del obraje en el nordeste y sud de la provincia, las estancias de Jiménez tampoco fueron beneficiadas por la «revolución del riego» que tocó a los departamentos cercanos a la capital. Como sin ambigüedad los retrata el censo económico social de 1895, los condóminos de Jiménez Segundo eran en su abrumadora mayoría pequeños productores campesinos que vivían de manera muy similar a la que estilaban sus ancestros. Y sin embargo, aprovechando la cercanía de las flamantes estaciones Chaupi Pozo, Gramilla y Ardiles del Ferrocarril Central Argentino, la «explotación clandestina» de los recursos del bosque, corazón comunal de aquellas propiedades colectivas, ya había despegado. Una reconversión productiva de estos comunales por excelencia se hallaba en acto y, tanto el código civil de 1871 como el santiagueño de procedimientos de 1876, proveían los instrumentos legales para que los condóminos «históricos» y «nuevos», los mejor posicionados entre ellos, la aprovecharan en beneficio propio. ${ }^{12}$ En el mismo sentido, la profesionalización de la agrimensura aportaba seguridad y garantías a la nueva forma de dominio que se buscaba imponer. ${ }^{13}$

Empero, la tarea no se demostró tan sencilla. La otra cara de la moneda que nos revelan los expedientes de archivo es que la división de condominios debió sortear una carrera de obstáculos, entre los cuales sobresalieron la resistencia de numerosos compartes y las dificultades de los pretendientes al reparto para acreditar su condición de dueños. Como dijera en 1917 uno de los abogados involucrados en el juicio de división de Los

10. Tasso, Alberto, Ferrocarril..., cit.; Tenti, María Mercedes, La formación de un estado periférico. Santiago del Estero (1875-1916), Santiago del Estero, Ediciones Universidad Católica de Santiago del Estero, 2013.

11. Rossi, María Cecilia y Guillermo Banzato, «Redefiniendo las fronteras y las formas de ocupación de las tierras del antiguo Copo en Santiago del Estero (desde el siglo XVI a mediados del XIX», Investigaciones y ensayos, núm. 64, 2017, pp. 29-72; Rossi, y Juan Antonio Rízolo Burgos, «Las leyes sobre tierras públicas en Santiago del Estero. 1858-1862», Banzato, Guillermo y Graciela Blanco. La cuestión de la tierra pública en Argentina: a 90 años de la obra de Miguel Ángel Cárcano, Rosario, Prohistoria Ediciones, 2009, pp. 133-162.

12. Cuando hablamos de «nuevos condóminos» nos referimos a inversores externos que adquirían derechos y acciones tales de formar parte de la estancia indivisa.

13. Ver al respecto Pro Ruiz, Juan, «Mensuras, catastro y construcción estatal». Introducción a Garavaglia, Juan Carlos y Pierre Gautreau (eds.), Mensurar la tierra, controlar el territorio. América Latina, siglos XVIII y XIX, Rosario, Prohistoria, 2011, pp. 13-26; Cacciavillani, Pamela, De propiedad comunal a propiedad individual. El régimen jurídico de la propiedad en Córdoba 1871-1885, Tesis de doctorado, Facultad de Derecho, Universidad Nacional de Córdoba, 2018, cap. 2, pp. 63-96. 
Gallardos —el ejemplo que habremos de profundizar- existían serios riesgos de terminar

como la [estancia indivisa] de Sotelos o tantas otras, que desde hace más de veinte años vagan por los tribunales sin encontrar juez que les ponga punto final, haciendo crear incertidumbre en los que actualmente viven, aquellos que, con derecho o sin él, de buena o mala fe, se creen dueños u otorgan poderes. Tenemos que en este juicio se ha desvanecido la calidad de comuneros de muchos de los pretendientes que se han presentado sin otro justificativo que el de decir aquí estoy yo. ${ }^{14}$

Y, en efecto, en 1917 ya eran más de dos centenares de presuntos condóminos, representados por cuatro abogados diferentes, los que decían tener derechos en la estancia Los Gallardos. Desconocemos en qué momento el proceso concluyó por fin y cuántos de los pretendientes consiguieron acceder a una parcela, pero es muy posible que sólo una minoría lo lograra. Con razón, en 1946, Ricardo Ríos asimilaba la situación de muchos condóminos con la de los agregados. Pasadas varias generaciones, ya no era posible «realizarse la división sin correr el riesgo de la exclusión ilegítima de su condueño, situación limítrofe con el despojo». ${ }^{15}$

\section{La estancia de Los Gallardos en su entorno regional}

En el noroeste de la actual provincia de Santiago del Estero, hacia el límite con San Miguel de Tucumán, se conformaron tempranamente importantes estancias que tenían por titulares a personajes notables y a órdenes religiosas (jesuitas, dominicos y mercedarios). Una de las razones que volvían estratégica la región era la actividad del camino del Palomar, desde fines del siglo XVI alternativo al Real y «ruta de Santiago» que llegaba directo hasta Jujuy esquivando la ciudad de San Miguel. A la vera del camino, poderosos personajes fundaron rentables establecimientos rurales como los de Tenené, El Palomar y Vitiaca, que abastecían a los viandantes y fungían como estructuras defensivas frente a las incursiones mocovíes. ${ }^{16}$ Héctor Peralta Puy ha reconstruido con minucia los traspasos de estas estancias que vivían del tránsito carretero y que abastecieron posteriormente a los ejércitos independentistas: que los más conspicuos representantes de la élite santiagueña

14. Archivo Histórico de Santiago del Estero (en adelante AHSDE), «Pedro Bisgarra y otros sobre mensura y división de la estancia Los Gallardos», Mensuras de Jimenez 2. vol. 1, exp. 1415, f. 247.

15. Ríos, Ricardo, «La posesión precaria agobia y destruye el espíritu. Títulos y antedentes de la propiedad Chupilta. Original procedimiento para establecer la extensión», Revista de la Junta de Estudios Históricos de Santiago del Estero, vol. 3, núm.7-10, Santiago del Estero, 1945, pp. 85-103 (cita en p. 87).

16. Este camino acortaba considerablemente los tiempos de viaje hasta Jujuy y desde allí a Potosí. Los vecinos de San Miguel de Tucumán bregaron por el abandono del camino — que esquivaba su ciudad— desde 1718, iniciando un conflicto centenario con los santiagueños que dejó abundante huella en las actas capitulares del siglo XVIII. Héctor Peralta Puy ha seguido el traspaso de las estancias de Palomar y Tenené hasta el siglo XIX, siempre en manos de grandes figuras de la elite santiagueña. 
mantuvieran —y luego ampliaran por compra de tierras fiscales— sus inversiones allí en el siglo XIX, hablaría de cierto dinamismo de la zona de Jiménez en años anteriores a los que aquí focalizaremos. ${ }^{17}$

Aunque probablemente en otra escala, entendemos que también los campos comunes — que coexistían con estas grandes estancias y no eran nada pequeños - participaban de una economía que iba más allá de la mera subsistencia, aunque sus dueños no fueran individuos sino colectivos de parientes. ${ }^{18}$ Los Gallardos, Los Sotelos, Los Días, Ojo de Agua, Los Gómez y Los Ardiles, entre otras, eran algunas de las comunidades indivisas que fundían tierras y linajes.

Los orígenes y el devenir de aquellos campos comunes parecen muy semejantes. Los Gallardos, Los Sotelos y Los Días habían surgido a partir de compras de mercedes a particulares fines del siglo XVII, mientras que Los Ardiles se había formado en 1742 en una porción de tierras adquirida al convento de La Merced. Sus siempre recordados fundadores -Andrés Gallardo, Jacinto Sotelo, Pascual Días, Francisco Ardiles- compartían un mismo perfil social: eran soldados, españoles de pocos recursos que buscaban asentarse en el entorno rural y que alternaban el trabajo campestre con las fatigas militares. ${ }^{19}$ Nótese que no habían sido ellos mismos los beneficiarios de mercedes, las habían comprado. Sin embargo, todos contaban con títulos y los más puntillosos se habían ocupado incluso de mensurar las tierras para habilitar la posesión.

Sus descendientes, no obstante, deberían renovarla en varias oportunidades. También en este punto la historia de las propiedades reconoce los mismos jalones: se hicieron mensuras a principios de la década de 1820 y sobre todo hacia 1837 , cuando un decreto de Deodato de Gondra ordenó el saneamiento de los títulos antiguos. ${ }^{20}$ Como es de imaginar, las nuevas mensuras no hicieron más que aumentar los solapamientos territoriales entre las estancias, avivando los conflictos por linderos entre los vecinos. Las superficies inmensas y difusas sobre las que los dueños colectivos sostenían señorear redefinían sus

17. Héctor Peralta Puy siguió a las distintas generaciones de dueños de las grandes estancias de Palomar y Tenené. Si Alonso de Alfaro era el propietario más notable en la primera mitad del XVIII, a fines del siglo lo serían Iramain y Santillán. Según el autor, el ganado de Tenené sirvió en la segunda década del siglo XIX para mantener la guarnición de blandengues del Fortín de Abipones. A partir de 1828 Tenené pasó por venta a otro gran personaje de la elite santiagueña, don Blas Achával, en la suma de $\$ 6.000$, un precio muy elevado en vistas de las inversiones realizadas por la familia Iramain. Peralta Puy, Héctor, «El camino del Palomar y su influencia en el poblamiento y su influencia en el poblamiento y evolución territorial del actual departamento Jiménez, provincia de Santiago del Estero, 1753-1828», disponible en $<$ https://unse.academia.edu/H\%C3\%A9ctor FranciscoPeraltaPuy>.

18. Sobre la historia más temprana de Los Gallardos y Ojo de Agua, ver Farberman, Judith, «Dueños, agregados, derechos de propiedad», cit. y, de la misma autora, «Las tierras mancomunadas...», cit.

19. Andrés Gallardo y su hijo pusieron en primer plano la «mucha obediencia» demostrada en el servicio de la frontera. Cabe destacar que, aunque señores de tierras abundantes, pocos bienes les dejaron a sus herederos. Si hemos de creer en uno de los vástagos de Andrés, el patriarca murió dejando a sus hijos «pobres sin remedio alguno». AHSDE, Tribunales, Leg. 4, expediente 53. 1826. Andrés Gallardo, Títulos de su propiedad.

20. Durante el gobierno de Juan Felipe Ibarra, una disposición de Deodato Gondra de 1837 ordenó deslindar y mensurar las propiedades habidas con títulos antiguos (AHSDE, Trib. 19 bis, 106, 1837). La medida, cuyo objeto era la recaudación fiscal, generó una verdadera explosión documental en la provincia. 
fronteras cada vez que se las medía, obligando ocasionalmente a los pobladores al abandono de casas y rastrojos.

Del conjunto de conflictos entre dueños colectivos, los que tuvieron lugar entre Gallardos y Ardiles marcaron hitos en las respectivas historias familiares, posicionando en las memorias genealógicas a los representantes de los compartes en los pleitos judiciales. Quizás el primer capítulo de esta contienda fuera el que tuvo lugar en 1770 —durante la primera mensura de Los Gallardos-y que alcanzó su clímax en 1838 — cuando tocó a los Ardiles medir su estancia—. ${ }^{21}$ Tres razones volvían controvertida la definición de los linderos y el cálculo de la superficie: el desacuerdo sobre la longitud de la legua (de 6.000 varas para Los Gallardos y de 5.000 para Los Ardiles), la inexistencia de los títulos de la estancia del convento mercedario — de la que se desprendía Los Ardiles- y la localización de los puntos extremos de aquélla.

La áspera discusión fue zanjada a partir de la convocatoria de ocho testigos ancianos que acompañaron al comisionado al «alto de la barranca» y al «sitio de Garzón», que separaban Los Ardiles de Los Días y Los Gallardos respectivamente. Aunque el sitio de Garzón se hallaba abandonado en 1838 — «montuoso» y con sus casas «botadas», al decir de los testigos- en el pasado había sido un «rodeo muy poblado». Siete compartes de Los Gallardos habían tenido allí sus ranchos — entre los cuales el padre del actual «tutor»- mientras que un «ciego arpero» de nombre Tiburcio Alderete había sido «puesto con licencia de don Nepomuceno [Paz] porque en aquel tiempo la madre de dicho Paz era la tutora de estos Ardiles». Tanto el agregado Tiburcio como don Celidonio Alderete, padre del tutor de Los Gallardos, habían «poceado», en el sitio. No era un detalle: cavar el pozo para la obtención de agua era el acto de posesión más eficaz y elocuente que podía tener lugar. Un dueño y un agregado de los dueños rivales habían procurado asegurar los derechos de su grupo sobre el terreno litigioso que, salomónicamente, fue dividido entre los dos grupos de parentesco. Un mojón de algarrobo blanco refrendó el acuerdo que convirtió a algunas familias de Los Gallardos en arrendatarias de Los Ardiles.

De manera que, mientras la estancia de Los Gallardos fue un campo comunero, los mayores esfuerzos de sus compartes se dirigieron a defender sus linderos, el «terruño de su apellido», ${ }^{22}$ como con elocuencia dijera un vecino de otra estancia indivisa, poco distante de la de nuestro ejemplo. Los argumentos desplegados en los pleitos enfatizaban el «trabajo en comunidad», incluso en las sementeras, y entendemos que no se trataba de un mero artificio retórico. ${ }^{23}$ También otras disputas sostenidas por los «hermanos»

21. AHSDE, Tribunales, Leg. 4, expediente 53. 1826.; AHSDE, Tribunales, Leg. 20, expediente 40. 1838. Alderete Celidonio. Sobre nulidad de una mensura.

22. La elocuente expresión le pertenece a don Ventura Días, «tutor» de la estancia indivisa de Los Días, limítrofe con Los Gallardos, en 1798. Trabajamos sobre este caso en Farberman, Judith, «Dueños, agregados...», cit. y en «Los avatares...», cit.

23. En una denuncia presentada en 1811 por varios compartes de Los Gallardos, se afirmaba que como «herederos de la estancia de «sus mayores», siempre habían «vivido en comunidad trabajando en su adelantamiento y nuestro sostén respectivo, aprovechándonos de una isla pingüe y feraz, que hoy era mui bastante para potrerillos, cercados y chacaras». AHSDE, Trib. 2, leg. 65, 1811. 
— como se daban en llamar- permiten inferir la solidez interna del grupo, al menos cuando se trataba de lidiar con personajes a los que se juzgaba «intrusos» o abusivos. ${ }^{24}$

Nos toca ahora dar un salto en el tiempo y aproximarnos al momento de la división de la propiedad colectiva, núcleo de este artículo. A fines del siglo XIX, Los Gallardos se hallaba en su mayor parte en el departamento de Jiménez Segundo. ${ }^{25}$ En comparación con la breve semblanza colonial y temprano decimonónica que hemos ofrecido, el panorama que nos muestran los dos primeros censos nacionales es de declinación de toda la zona. ${ }^{26} \mathrm{Al}$ igual que otros departamentos santiagueños como Jiménez Primero, Atamisqui, Río Hondo y Silipica, Jiménez Segundo había perdido buena parte de su población entre 1869 y 1895 . Si en la fecha del primer censo vivían en el departamento unos 8.518 habitantes, en 1895 este número se había reducido a 5.807 y, de manera dramática, si Jiménez Segundo aportaba en 1869 un $6 \%$ de la población provincial, esta participación había descendido al 3,5\% en 1895.

No es novedad que Santiago del Estero era tierra de emigración, reservorio de mano de obra de la «Argentina moderna» y que, en rigor, lo había sido secularmente, ya desde tiempos coloniales. Sin embargo, este componente estructural de la economía provincial era aún más evidente en estas decaídas zonas rurales. Las migraciones se dirigían hacia departamentos más prósperos — los forestales, los cercanos a la ciudad-y especialmente hacia Buenos Aires y Tucumán, donde el cultivo de la caña de azúcar reclamaba braceros. Como era esperable, la tan esperada inmigración extranjera en nada compensó la pérdida de población local y nuestro departamento de interés - como buena parte de los de la provincia - se hallaba poblado en su abrumadora mayoría por santiagueños. Así pues, al doblar el siglo XIX, Jiménez Segundo mostraba una postal muy poco «moderna», caracterizada por el predominio de una agricultura y ganadería en manos de muy pequeños productores, que coexistía con actividades extractivas no registradas en los censos de la época, pero sí en los juicios de división de condominios.

Hecha esta síntesis, acerquemos la lente un poco más y enfoquémonos en el distrito de Ardiles, que hacia 1895 albergaba la mayor parte de la superficie de Los Gallardos. Las cédulas censales y los boletines de agricultura y ganadería de aquella fecha y de aquel distrito vendrán en nuestro auxilio para mejor contextualizar el proceso de disolución de la estancia e identificar a algunos de los condóminos que tomaron parte en él. ${ }^{27}$

24. En Farberman, Judith, «La mancomunión...» analizamos el conflicto de los compartes de Los Gallardos con su presunto agregado Valerio Brandán, luego fundador de un campo común cercano.

25. La zona de nuestro interés formaba parte del dilatado curato rectoral en tiempos coloniales. La información que encontramos sobre la conformación del departamento es contradictoria, pero entendemos que en 1887 ya existían dos secciones de Jiménez, Primera y Segunda y que en 1911 éstas se unen cediendo parte de la superficie a otros departamentos. En todo caso, desde 1911 la mayor parte de la superficie de Los Gallardos queda en el departamento de La Banda con sectores más pequeños en el de Río Hondo. Ver Basualdo, Mario, Rasgos fundamentales de los departamentos de Santiago del Estero. Un documento para su historia, Santiago del Estero, 1981, tomo II, p. 12.

26. No consideramos el censo de 1914 porque para entonces se habían redefinido los límites de Jiménez 2 y la estancia que nos interesa se incluía — en su mayor parte — en el departamento de La Banda.

27. Las cédulas del Segundo Censo Nacional de 1895 se hallan disponibles on line en Argentina censo 
En 1895, vivían en Los Ardiles 801 almas — cerca del 14 \% de la población de Jiménez 2 en el mismo año-. Salvo por la sobreabundancia de «labradores» — que comentaremos más adelante- - y la paridad entre los sexos, esta pedanía se diferenciaba muy poco de otras del Departamento. Era un distrito netamente rural, salpicado de casas dispersas de «madera, zinc y paja», ranchos en otras palabras, que alojaban bajo un mismo techo a grupos familiares de alrededor de 7 individuos. Por otra parte, el registro de una mayoría de «propietarios de bienes raíces» entre los adultos de ambos sexos —característico del departamento- surge también en Ardiles, aunque el censista local haya levantado estos datos con evidente desprolijidad y criterio por demás errático. ${ }^{28}$

Este predominio de supuestos propietarios — «poseedores», en rigor- debe relacionarse con los datos ocupacionales — que sólo excepcionalmente registran categorías dependientes como las de «jornalero» $\mathrm{y}$ «sirviente»— $\mathrm{y}$, por supuesto, con la existencia de condominios. Allí los poseedores eran sin duda muy numerosos, hablamos de más de doscientas personas sólo en Los Gallardos, aunque el censo, por su objeto, no refleje la fragilidad de los derechos de la mayoría.

Por cierto, también en los distritos cercanos de Los Gómez, Jiménez y Ojo de Agua, así como en el limítrofe departamento de Río Hondo, existían otros condominios, que iremos mencionando a su tiempo. Algunos condóminos de Los Gallardos (pocos, en realidad) tenían dispersos sus derechos y acciones también en otras estancias indivisas de la zona y figuran por tanto en más de un listado de agricultores y ganaderos de Jiménez Segundo. Acaso la nota que diferenciaba Ardiles de los restantes distritos de Jiménez Segundo fuera la abrumadora mayoría de «labradores» y de «teleras» que, en principio, contrastaría con el perfil mixto de otros que hemos analizado. ${ }^{29}$ Sin embargo, se trata de categorías ocupacionales a tomar con pinzas y la información del Censo Económico Social permite relativizarlas: los 54 productores registrados en el Boletín de Agricultura se encuentran casi todos en el de ganadería (que suma 87). De esta suerte, tampoco en este

nacional, 1895. Database with images. FamilySearch <https://FamiliySearch.org:21August2017>. El Censo Economómico Social (en adelante CES), en AGN, legajos 242 y 243.

28. El censista de Los Ardiles oscila entre consignar la propiedad raíz de hombres y mujeres adultas, solteras y casadas, y la de toda la población empadronada. Es poco sistemático y registra en algunos cuadernillos incluso a los niños como «poseedores de propiedad raíz». De todos modos, nos sigue pareciendo destacable que en Jiménez 2 la propiedad raíz fuera evaluada en 311 por mil, encontrándose entre los valores más altos de la provincia. En líneas generales, siguiendo a Hernán Otero, en las provincias más pobres, los valores proporcionales de acceso a la propiedad raíz eran más altos que en las más dinámicas. Así eran del 262 por mil en La Rioja contra el 69 por mil en Buenos Aires. Otero, Hernán, Estadística y nación. Una historia conceptual del pensamiento censal de la Argentina moderna, 1869-1914, Buenos Aires, Prometeo, 2006, p. 286.

29. Las cédulas censales de 1895 registran 197 «labradores» (161 de los cuales de sexo masculino), 119 «teleras» y 11 «teleros». Prácticamente aquí se agota la nomenclatura de ocupaciones ya que apenas dos «estancieros» fueron empadronados y ningún «criador», categoría corriente en pedanías cercanas. Por desgracia, las cédulas de 1869 no están separadas por distritos con lo que se dificulta la comparación de la distribución por ocupaciones. En Farberman, Judith, «Dueños, agregados...», cit., analizamos los datos de dos distritos cercanos a Ardiles: Ojo de Agua y Los Gómez. Efectivamente, en ambos la participación de «estancieros» y «criadores» equilibra la de «labradores». 
aspecto nos apartaríamos en sustancia de lo que ya conocido: un patrón típicamente campesino, no importa si en el interior de grandes estancias. ${ }^{30}$

La población de Ardiles se distribuía fundamentalmente en dos establecimientos: Los Ardiles y Los Gallardos. Aunque en los extractos de títulos se sostuviera que la segunda había mantenido su integridad territorial desde su fundación en 1691, no sabemos a ciencia cierta cuál era su superficie exacta. Mientras que los títulos de la merced fijaban las dimensiones en una legua de frente y tres fondo — unas 8.000 ha-, los documentos más tardíos arrojan medidas que varían entre las 11.453 ha de la mensura de 1889 y las 6.400 que figuran en un recibo de pago de la contribución directa de $1917 .{ }^{11}$ Como fuera, hablamos de una gran superficie, cubierta en buena parte por monte chaqueño y salpicada de «poblaciones», como llamó a los caseríos y explotaciones con los que se topó a su paso el agrimensor Emilio Lacube, autor del único croquis de mensura que hemos hallado hasta ahora. De estas «poblaciones», las tres «principales y más antiguas» eran Alderetes al sudeste, Quebrachos al norte y Taperas al noreste; quizás Banegas y Tunales, señaladas ambas por el agrimensor, fueran más recientes. En el croquis puede también observarse la traza del camino que conducía a Tucumán, el deslinde del ferrocarril y una gigantesca «isla» — que Lacube llamó playa— en medio del río Dulce. Creemos reconocer allí los terrenos que los antiguos compartes de la estancia disputaron en 1811 con sus vecinos de entonces, los dueños colectivos de Chauchillas. En estos terrenos feraces, que cambiaban de lugar con las crecientes convirtiéndose «en bañados y numerosas lagunas» (al decir de Lacube), sembraban su maíz los compartes de los Gallardos y quizás lo mismo hicieran sus herederos. ${ }^{32}$ Por fin, el agrimensor también encontró en su recorrido, cerca del «Alto de la Barranca», que marcaba el antiguo límite con Los Días, una «sucesión de cerros y de quebradas cubiertas de montes espesos», parte del monte de Los Gallardos.

30. Para proveerle al lector una idea aproximada, un productor promedio entre los registrados por el Boletín de Ganadería de Ardiles poseía 31 vacas, 3,8 bueyes, 7,2 caballos, 6,9 burros, 2,8 mulas, 29.4 ovinos, 8.3 cerdos y 26.8 cabras mientras que un labrador, siempre «propietario», contaría con 1,4 cuadras sembradas de trigo y 2,4 de maíz. AGN, CES 1895, 243. Se trata de valores incluso algo superiores a los de Ojo de Agua y Los Gómez, que estudiamos en «Dueños...», cit., donde los «criadores» y «estancieros» tenían una mayor participación relativa que en Ardiles según las cédulas censales. Traducido a pesos, el promedio de patrimonio ganadero era en Ardiles de 1.038 \$, cifra cercana a la de Ojo de Agua pero que casi doblaba la de Los Gomez. Tomamos los precios del ganado de Gancedo, Alejandro, Memoria histórica y descriptiva de la provincia de Santiago del Estero, Buenos Aires, Stiller y Laas, 1885, p. 185.

31. El título de Los Gallardos en AHSDE, Tribunales 4, expediente 53, 1826. Se trataba de terrenos mucho mayores que las suertes de estancia pampeanas (de algo más de 2.000 ha) por tener 3 leguas de fondo (18.000 varas), cuando tenían costa de río, en lugar de legua y media (9.000 varas). Por otra parte, mientras la medida típica del frente de estancias pampeanas era de media legua, Los Gallardos triplicaban esa cifra. Calculamos la superficie en hectáreas siguiendo a Garavaglia, Juan Carlos, «¿Cómo se mide la tierra? Las mensuras en el Río de la Plata, siglos XVII a XIX», cf. Garavaglia, Juan Carlos y Pierre Gautreau (eds.), Mensurar la tierra, controlar el territorio. América Latina, siglos XVIII y XIX, Rosario, Prohistoria, 2011, p. 29. La mensura de Emilio Lacube se incluye en AHSDE, Mensuras de Jiménez, vol. 1, exp. 183, s/f. y el recibo de pago de la contribución directa en AHSDE, Mensuras de Jiménez, vol. 2, exp. 1415.

32. Ya se hizo mención a la disputa por la «isla», en 1811 páginas atrás. AHSDE, Trib.2, Leg. 65. 1811. 
Como se hacía de ordinario en las operaciones de mensura, el perito solicitó a los vecinos colindantes que presentaran los títulos para acreditar su propiedad. Así fueron convocados don Felisberto Robles, «uno de los dueños y administrador de Los Sotelos», Andrés Días, «supuesto colindante al nordeste» y Lino Bisgarra «administrador y uno de los dueños de Ardiles». Estos tres personajes —-todos ellos a la cabeza de los boletines de agricultura y ganadería de Los Gómez y Ojo de Agua y nada, me equivoqué acumuladores de derechos y acciones de otros condóminos- descendían de los fundadores de sus respectivas estancias indivisas, a las que ya nos referimos. La novedad era el papel del administrador, figura regulada por el Código Civil de 1871 para gestionar las cosas comunes. Cuánto de los antiguos «autores» de los campos comuneros quedaba en estas figuras es una incógnita todavía por despejar.

\section{La interminable división del condominio de Los Gallardos}

¿Por qué motivos la indivisión de la tierra había configurado un horizonte de largo plazo para los compartes? No suele ser explicado lo que es obvio para todos. Sin embargo, en algunas (raras) ocasiones, los dueños dejaron su testimonio en testamentos o pleitos judiciales. No partían «por ser muchos», «por la cortedad de las tierras», «para servir [éstas] de hospital en las indigencias», «porque puedan seguir viviendo todos, disfrutando de ellas en unión y conformidad». He aquí algunas de las razones que surgen al pasar en las fuentes de los siglos XVIII y XIX..$^{33}$ Nos hablan, sobre todo, de la necesidad de ahuyentar la pobreza, o de restituir la equidad que la naturaleza amenazaba al inundar ciertos terrenos o salinizar otros.

Existía, pues, una racionalidad en la indivisión, que un abogado podía formular de manera más técnica, como lo hizo el representante de los condóminos de Puesto de Rojas a fines del siglo XIX. Según afirmaba, los diversos grupos de pobladores de la estancia se mantenían «hasta cierto punto divididos (...) en sus posesiones respectivas», pero gozaban «en común y armonía de ciertas cosas como aguadas, arroyos, pozos etc. que nunca sería conveniente ni posible dividirlas ni adjudicarlas a persona determinada». Lo que se hallaba «establecido por la naturaleza misma», seguía el abogado, debía permanecer «indispensablemente en común para beneficio de todos». ${ }^{34}$

La situación de Puesto de Rojas, distante geográficamente de Los Gallardos, era la de otras tantas «innumerables estancias», en las que la «división de hecho» —o sea, la sectorización que alojaba a distintos grupos de poseedores- coexistía con la «indivisión forzosa» dictada por la naturaleza — y aquí quizás el juicio del abogado fuera demasiado determinista- Por otra parte, aunque no lo mencionara, también los bosques habían compartido hasta finales del siglo XIX un status similar al de las fuentes de agua. La eco-

33. Sobre la racionalidad de la indivisión, $c f$. Judith Farberman, «Los avatares...» y «El mancomún...».

34. AHSDE, Mensuras, de Quebrachos, vol. 2, Sanchez Domingo, Mensura y división de terreno, 1894. 
nomía silvopastoril de los compartes — al igual que hoy, el ganado criollo se criaba a monte- era habilitada por aquellas amplias superficies boscosas.

Algunas divisiones de condominio cuyo final conocemos — como la de Ojo de Agua, que analizamos en otra parte- contemplaron las «divisiones de hecho» y las limitaciones ambientales, dejando porciones no despreciables de terreno en «mancomún general». ${ }^{35}$ Viceversa, en otros casos, algunos condóminos enajenaron por su cuenta las superficies de bosque común que suponían que les serían adjudicadas, aún antes de que se efectivizara la división. ${ }^{36}$ Como fuera, incluso en los casos mejor consensuados, la división de condominio sólo podía ser ruinosa para una mayoría de campesinos cuya vida material era por lo menos frágil.

En la práctica, hemos encontrado que el condominio cesaba o bien por iniciativa de uno o más compradores «masivos» —y generalmente externos- de derechos y acciones, o bien cuando eran los condóminos históricos —en rigor, un grupo de ellos, habitualmente más próspero- los que deseaban ponerle fin. ${ }^{37} \mathrm{El}$ caso de Los Gallardos ejemplifica ambas vías, ya que la primera terminó por frustrarse. Se suponía que los condóminos que no hubieran vendido con precedencia sus derechos y acciones podrían teóricamente acceder a una parte proporcional de las tierras, siempre y cuando acreditaran su condición de tales. En este sentido, uno de los métodos adoptados para organizar el reparto consistía en la reconstrucción genealógica y en la asignación retrospectiva de la superficie que habría tocado a cada miembro del grupo de parentesco de haberse realizado oportunamente el reparto. Fue éste el procedimiento seguido en Ojo de Agua y también en otras estancias indivisas menos antiguas: el resultado, naturalmente, perjudicaba progresivamente a los herederos de las familias más numerosas y a los condóminos más jóvenes. Por lo tanto, si la división llegaba a buen puerto, el despojo esperaba también a algunos tradicionales e incuestionables «dueños colectivos» (a menos que la adquisición de derechos y acciones a otros parientes compensaran la fragmentación hereditaria). ${ }^{38}$

Hechas estas aclaraciones, regresemos a Los Gallardos y situémonos en 1889, cuando tuvo lugar la primera solicitud de división del condominio. ${ }^{39}$ Entendemos que, para entonces, las relaciones entre los condóminos lucían mucho más tirantes que medio siglo atrás, cuando la comunidad en pleno se disputaba los terrenos confinantes con los veci-

35. Ver Farberman, Judith, «Agregados...», cit. El lote común de Ojo de Agua medía 121 ha. y en él se localizaba la aguada principal de la estancia.

36. Así ocurrió en la estancia Vinalito, del mismo departamento de Jiménez 2. AHSDE, Mensuras de Jiménez, vol. 3, 1929.

37. Tampoco es de excluir que la división de condominios obedeciera a la mayor vitalidad de las unidades menores que componían las estancias indivisas, las «poblaciones». Las dificultades que atravesaban las administraciones de condominios también podrían vincularse con el crecimiento de los sectores en que se dividía la estancia.

38. Conseguimos reconstruir la división del condominio de Ojo de Agua a través de una genealogía de dos centurias en Farberman, Judith, «Del mancomún al condominio y de la agregaduría a la comunidad de parentesco. Indivisión, posesión y propiedad en Santiago del Estero (Argentina), siglos XVII a XX». XVI Congreso de Historia Agraria SEHA, Santiago de Compostela, 20-23 de junio de 2018.

39. AHSDE, Mensuras de Jimenez, vol. 1, 183. 1889. 
nos de Los Ardiles y la división era un horizonte impensable. Para seguir ordenadamente dos de las cuestiones centrales que se plantean en los juicios de división - la de quiénes eran los «verdaderos condóminos» y la de la conveniencia y oportunidad del juicio- organizamos la exposición del apartado en los tres momentos que las fuentes nos permiten advertir. El problema de la explotación de los bosques, a nuestro parecer el móvil fundamental de las iniciativas de división, será tratado separadamente.

\section{- 1889}

Como se anticipó, la mensura de Los Gallardos fue solicitada por tres personajes externos a la membresía histórica de la estancia indivisa. Ramón Pouza, José Hermansson y Napoleón Ávalos habían adquirido su porción de derechos y acciones de Nicolás Tolentino Ovejero, uno de los condóminos de Los Gallardos de quien poco sabemos. ${ }^{40}$ Aunque para el agrimensor Emilio Lacube aquella compra convertía al trío en propietario exclusivo de la estancia, un grupo de «pobladores y agregados» — palabras de Lacube- denunció de inmediato que el vendedor Ovejero «no era el solo dueño de Los Gallardos». ${ }^{41}$

Nada de esto, sin embargo, impidió la realización de la mensura. Como en el pasado, se trató de un gran acontecimiento, que congregó a un público numeroso y se prolongó durante varios días. Los tiempos, empero, habían cambiado y medio siglo después del litigio con los Ardiles, la agrimensura había redoblado su papel protagónico en la delimitación de las propiedades. Las operaciones habían dejado de descansar en baqueanos, hombres prácticos y vecinos a menudo parciales, que medían ayudándose con brújula y cuerda, para ser confiadas a profesionales capaces de trasladar al papel y expresar en números las superficies antes estimadas vagamente. El Departamento Topográfico, varias veces refundado en la provincia, sería en adelante un actor de peso, marcador de la expansión de las actuaciones del estado e instrumento fundamental para la enajenación de tierras fiscales. ${ }^{42}$

Los «pobladores y agregados» que en «numerosa comitiva» habían hostilizado la tarea del agrimensor eran liderados por unos tales Washington Heredia y Atanasio Rodríguez. De Heredia apenas sabemos que era un condómino — quizás recientemente unido a Los Gallardos - a quien, sin embargo, se le había confiado la custodia de parte de los

40. Andrés Hermansson y Napoleón Ávalos están invirtiendo en la zona a fines del siglo XIX, suponemos que interesados en la explotación forestal. Hermansson aparece como el titular de un antiguo campo común, Los Días, disuelto en estos años. Ávalos es uno de los compradores masivos de acciones de la ya mencionada estancia de Vinalito y «condómino inversor», en Ojo de Agua. En Vinalito fue denunciado por explotar los bosques antes de la conclusión del juicio. AHSDE, Mensuras de Jiménez, vol. 3, 1929.

41. AHSDE, Mensuras de Jiménez, vol. 1, exp. 183, 1889, f. 14.

42. Hasta 1869 desempeñaba las funciones de un Departamento Topográfico el Agrimensor de la Provincia. El Departamento fue fundado en 1869 y refundado en 1877 y en 1889. Es sintomático de la importancia creciente de la agrimensura la multiplicación de solicitudes para ejercer como peritos en la provincia a partir de 1880 . 
títulos primitivos; Atanasio Rodríguez — a quien el agrimensor calificaba de «jefe» del anterior - decía por su parte ser a la vez vecino colindante — como copropietario de Los Días- y condómino de Los Gallardos. ${ }^{43}$ Según Rodríguez, «la mayoría de ellos [de los condóminos de Los Gallardos] que son ciento y tantos» le habían vendido «media legua de frente por dos leguas de fondo en medio de los linderos que expresan los títulos que otorgaron». Por cierto, los papeles de Rodríguez no constan en el expediente y el agrimensor lo desacreditó a la vez como colindante y como propietario, aconsejándole que, en todo caso, aprovechara la ocasión de un saneamiento que no pagaría de su bolsillo. ${ }^{44}$

Interesa por ahora retener el dato de la presencia de ciertos personajes que venían realizando compras masivas de derechos y acciones en la estancia ya antes de la solicitud de división. La disgregación del campo común, por tanto, era un proceso ya en acto, aunque la iniciativa de mensura y división — promovida por sujetos relativamente externos al condominio- surgiera en 1889. Tres actores han aparecido hasta aquí: el trío promotor de la mensura a partir de la adquisición de derechos y acciones a un condómino «rico» (Tolentino Ovejero), Rodríguez y Heredia, tenedores también de una cuota supuestamente importante de derechos y acciones que resisten la mensura, y el grupo de condóminos, probablemente «históricos», que elevaron su protesta y cuyo peso e identidad resultan aún desconocidos en esta instancia. Al igual que en Ojo de Agua, los dos últimos actores vivieron (razonablemente) las operaciones de mensura como una amenaza y, en ese sentido, las expresiones «pobladores y agregados» de Lacube poco tenían de inocentes. Ambos términos se oponían al de «dueño» y «propietario», aunque no le tocara al agrimensor ocuparse de un problema que se resumía en pocas palabras: de los numerosos coherederos de la estancia indivisa, sólo algunos podrían acreditar sus derechos.

De todos modos, la mensura de 1889 fue desestimada por el Departamento Topográfico, que rechazó la longitud asignada a la legua correspondiente al fondo de la estancia —que debía ser de 5.000 y no de 6.000 varas como se aceptaba para el frente-. También el trío Hermansson, Ábalos y Pouza quedó fuera de juego por «carecer de personería para solicitar la división» y practicarse ésta «con títulos supletorios formados a petición de terceros extraños». ${ }^{45}$ La nulidad de la venta y el rechazo de la mensura cerraban un capítulo y abrían otro, cuya conclusión ignoramos, en el que las disputas internas entre condóminos fueron mucho más encarnizadas.

43. AHSDE, Tribunales, leg. 186, exp. 9. 1888. Ovejero Tolentino contra Washington Heredia por entrega de unos títulos de propiedad.

44. Anastasio Rodríguez fue, efectivamente, colindante en el sector norte de Los Gallardos; luego vendió sus derechos y acciones a Napoleón Taboada, otro personaje que campea en los juicios de división de Jiménez 2. Sin embargo, ni él ni Heredia figuran en los Boletines del CES, lo que daría a pensar en algún tipo de inversión especulativa en la zona.

45. Esta instancia de desconocimiento de las actuaciones anteriores fue promovida por un grupo de condóminos encabezado por Mercedes Nuñez, Francisco Gallardo y Antonio Orellana que exigieron la «nulidad de la venta de Los Gallardos». En 1906, la causa se hallaba en trámite en el Juzgado Federal. No hemos localizado el expediente y sólo lo conocemos de mentas. AHSDE. Mensuras de Jiménez, vol. 1, exp. 1415 (1905), f. 62 . 
El 5 de abril de 1905, en la estación ferroviaria de Chaupi Pozo, un grupo de 30 condóminos de Los Gallardos encabezado por Pedro Bisgarra apoderó al doctor Pedro Llanos para que los representara en el juicio de deslinde, mensura y división de la estancia. ${ }^{46}$ Entre originales y copias, 71 fojas de documentación, las mismas que le habían sido negadas a Ovejero quince años antes, fueron entregadas al abogado: en ellas se condensaba la larga historia de Los Gallardos desde su fundación.

Los iniciadores de la nueva causa decían compartir su parentesco directo con Mercedes Núñez, a quien identificaban como una de las nietas de don Andrés Gallardo. ${ }^{47}$ Aunque resulta improbable que los pretendientes fueran los bisnietos de quien ya era adulto dos siglos antes, podemos pensarlos como descendientes de un mismo tronco de parentesco, probables poseedores históricos de un mismo sector de la estancia. Por otra parte, estos condóminos se erigían en continuadores del ya aludido juicio contra Hermansson, Pouza y Ávalos, del que habían salido victoriosos al obtener la nulidad de la venta. Detectamos entre los miembros de este grupo a hombres de la administración -Abdón Rojas, Emilio Gil, Cándido Gómez- y hemos logrado localizar a doce de ellos en el censo económico social de $1895 .{ }^{48}$ No obstante hemos constatado ya que los patrimonios de los productores de la pedanía (y de Jiménez en general) eran modestos, debe considerarse que sólo se anotaba en los boletines a una porción muy pequeña de los adultos censados que, en términos relativos, seguía siendo la más rica. Así pues, no es abusivo pensar que este grupo de condóminos históricos gozaba de una mejor posición relativa que sus compartes.

Otros dos grupos, y algunos individuos sueltos con sus respectivos abogados, se sumaron a la liza en 1906. Aunque compuesto solamente por dos herederos de Tolentino Ovejero, Rufina Jiménez de Ovejero y Juan Pablo Ovejero se proclamaban «condóminos y poseedores» desde hacía medio siglo de «una gran zona», en Los Gallardos. Sin reconocer «los derechos que se atribuyen los iniciadores de la división», el par apoderó a don Baltasar Ávalos, personaje que luego desaparece de la contienda. ${ }^{49}$ Cabe destacar que

46. AHSDE. Mensuras de Jiménez, vol. 2, exp. 1415 (1905).

47. Aunque admitían que el fundador había tenido varios hijos, destacaban a tres de ellos: Andrea, esposa de un Orellana, Domingo y Concepción, casada con un Núñez.

48. Este censo incluye tres boletines que nos interesan: el de cercos, el de agricultura y el de ganadería. De los 12 condóminos de Los Gallardos representados por Llanos, tres figuraban en los tres boletines, cuatro en el de ganadería y cercos y dos en los de agricultura y cercos. Solamente dos condóminos fueron registrados en un solo boletín, el de ganadería: Telésforo Maldonado y Abdón Rojas. De esta pequeña muestra, Félix y Fabián Alderete se encontraban a la cabeza (entre los diez primeros) de los boletines de cercos y de ganadería; los restantes no tiene fortunas descollantes, aunque superan la media entre los ganaderos ( $\$ 1.547$ en promedio vs. \$1.338). En el boletín de cercos, en cambio, los productores de Los Gallardos están algo por debajo del promedio (\$147 vs 158). Vale la pena aclarar que no es difícil que muchos registros se nos hayan escapado: del listado de Llanos, sólo tenemos el dato del nombre y apellido por lo que el cruce de información no es tarea sencilla.

49. Desaparece el representante legal, mas no los Ovejeros. Uno de los proclamados descendientes de Tolentino se sumará a la comitiva de Carmelo Vidal en 1917. 
Ovejero no era un apellido común en el distrito de Ardiles y que medio siglo no era gran cosa para quienes se reclamaban miembros históricos de un condominio con antecedentes que se remontaban a dos centurias atrás: el censo de Ardiles 1895 registra 13 adultos de ese apellido - Juan Pablo entre ellos_ y también a Rufina, como si residieran en un mismo núcleo de población..$^{50}$ Por otra parte, un tal Modesto Ovejero, cuyo parentesco con Juan Pablo y Rufina desconocemos y que no vivía en el distrito de Ardiles, encabezaba a los labradores del boletín de agricultura de la pedanía (también figura entre los ganaderos, aunque sin descollar). En suma, creemos ver en este segundo y mínimo grupo a los descontentos con el resultado del desenlace de 1889.

Por último, el tercer grupo encontró su representante en Nicanor Salvatierra —otro personaje que ya hemos reconocido ofreciendo sus servicios en la zona y del que hay rastro abundante en el archivo—-. ${ }^{51}$ Compuesto inicialmente por seis condóminos que sostenían abonar los «derechos territoriales» y ser poseedores «ya directamente unos y por intermedio de hermanos y parientes otros», inferimos que se trataba de gente que vivía en otros sitios, quizás de condóminos no poseedores. De hecho, sus apellidos directamente no figuran en el censo de 1895 para el distrito de Ardiles y en varios casos detectamos que los poderes fueron firmados (o más bien, hechos firmar) en la provincia de Tucumán. Algunos de los interesados decían descender de otra nieta de Andrés Gallardo y otros se filiaban en Celidonio Alderete, el «autor» del campo común en 1838, mientras que otros más se limitaron a remitirse vagamente a la «herencia de sus antepasados» «sin presentar justificativo legal alguno» (SIC). Todos ellos, en cualquier caso, solicitaron ser convocados para elegir al agrimensor.

En 1909 la mitad de los miembros del último grupo — que sumó a otros posibles vecinos y parientes - vendió sus derechos y acciones a un tal Casimiro García, tucumano. Dos años más tarde, García había conseguido acumular, gracias a la evidente mediación de Salvatierra, los derechos y acciones de 34 presuntos condóminos de Los Gallardos. Previsiblemente, Salvatierra devino también en representante legal de García, a quien sus compras masivas convirtieron en condómino de la estancia..$^{52}$ Se trataba de un caso similar al de Pouza y compañía, aunque se hallara en juego un número mayor de vendedores munidos de derechos presumiblemente más dudosos, que Llanos y Ávalos se apresuraron a no reconocer.

50. Los Ovejeros son muy numerosos en otro distrito de Jiménez Segundo: Remes. Probablemente, de allí vinieran Nicolás Tolentino y sus parientes.

51. Nicanor Salvatierra, procurador sumamente activo, desplegaría también una carrera política importante a escala provincial. Parte de la junta revolucionaria que en 1908 trató de deponer al gobernador José D. Santillán, fue luego diputado nacional por el oficialismo en 1914 y candidato parlamentario en 1919. Alen Lascano, Luis, Historia de Santiago del Estero, Buenos Aires, Plus Ultra, 1996, pp. 471, 485, 492-493.

52. Vale la pena detenerse un momento en la modalidad en que tuvieron lugar estas operaciones, que fueron 9 en total. Tres de ellas involucraban a un único condómino, mientras que las restantes reunían agrupaciones de tres a nueve individuos, generalmente hermanos. En cinco casos, los vendedores incluyeron genealogías con algún detalle; en los restantes dominaba la vaguedad. Por fin, salvo en un caso, los vendedores recibían el dinero - $\$ 3.000$ en casi todas las operaciones - comprometiéndose a pagar de su cuenta por el saneamiento de los títulos, que incluía la mensura y la división. Casimiro García invirtió un total de \$28.000 en estas compras. 
Pasados doce años desde la apertura del juicio de división, ni siquiera se había nombrado al perito que efectuaría el deslinde. Sin embargo, mientras la división se estancaba, otras dos causas, sobre las que disponemos de menos información, corrían en paralelo. Al menos desde 1914 — y quizás antes — se produjeron varios incidentes en relación con la explotación clandestina del monte de la estancia mientras que, en fecha incierta, tuvo lugar un juicio por la administración del condominio, en manos de los iniciadores de la división.

A la vez, dos nuevos grupos de condóminos, esta vez multitudinarios, se sumaron a los representados por Llanos y por el defensor de ausentes..$^{53}$ En siete reuniones, convocadas entre junio y julio de 1917 en las estaciones de Ardiles y Alderetes, el procurador Carmelo Vidal logró hacerse apoderar por nada menos que 116 compartes, analfabetos casi todos, que aceptaron su representación frente al juez de paz. Algo similar hizo Enrique Canal Feijoo en las estaciones de Gramilla y Alderetes, también en julio de 1917. Este procurador, que parece ser el reemplazante de Nicanor Salvatierra, fue apoderado por 111 clientes, entre los cuales el tucumano Casimiro García. ${ }^{54}$

De esta suerte, en 1917, más de 250 sujetos — pues los había también quienes se presentaban por su cuenta- se decían condóminos de Los Gallardos. Una especie de contagio había cundido en la estancia, aunque a estos «nuevos» condóminos ya no se les exigiera que acreditaran su filiación. En efecto, en los extensos listados apenas si figuraban el nombre y el apellido de los pretendientes, sin duda alentados a anotarse en la carrera para participar de la división. O quizás, como sostuvo algún letrado, para evitarla sembrando obstáculos en el camino... De hecho, todo parece indicar que el incidente abierto para obtener la nulidad del juicio de división fue iniciado por el mismo Carmelo Vidal, representante legal del grupo mayoritario.

¿Cómo caracterizar a estos más de 200 condóminos? Los datos censales de 1895 ya habían quedado viejos en 1917, aunque logremos reconocer a algunos en las cédulas. No

53. La figura del defensor de ausentes pretendía salvaguardar los intereses de las personas que, encontrándose ausentes con presunción de fallecimiento o viviendo en domicilio desconocido fueran afectadas en sus derechos por la resolución que se dictara. Según se lee en Escriche, el ausente era «el que no está en el lugar de su domicilio o residencia ordinaria (...) Si alguno tuviese acción o derecho que intentar contra otro que se halla ausente (...) puede pedir que se nombre defensor o curador a sus bienes (...). Escriche, Joaquín, Diccionario Razonado de Legislación y Jurisprudencia, Paris, Francia, Rosa y Bouret, 1863, p. 308

54. Enrique Canal Feijoo, tío paterno del más conocido ensayista y escritor santiagueño Bernardo Canal Feijoo, aparece, al igual que Salvatierra, como un personaje sumamente activo entre 1890 y 1920 . De hecho, representa a varios grupos de condóminos en juicios de división de diferentes departamentos. Autor de un manual para jueces de paz de campaña de 1909, se presenta como «escribano público, ex secretario en propiedad de los juzgados de 1 instancia en lo civil y comercial y del crimen, interino de la Exma corte de justicia, ex adscrito al registro de contratos y de hipotecas, embargos e inhibiciones a cargo del señor Absalón Arias e Inspector de juzgados de Paz durante los años 1903 y 1904». Ello nos permite pensarlo como un procurador conocedor del terreno y muy preocupado por la ineficacia de leyes pensadas para otras realidades provinciales y de las autoridades locales que, por falta de formación, entorpecían aún más el progreso de las causas judiciales. Ver Canal Feijoo, Enrique, Manual para jueces de paz de campaña, Santiago del Estero, Talleres Gráficos de R. Ribas y Cia, 1909, del que sólo parece haberse publicado la primera parte. 
obstante, podríamos inclinarnos a pensar que, como sostenía Enrique Canal Feijoo, entre ellos se encontraban los más pobres entre los históricos dueños colectivos. Un segundo denominador común que creemos intuir es que, a diferencia del grupo de Llanos, ligado a la administración del condominio, estos campesinos fueron convocados y movilizados para reclamar por sus derechos de propiedad. Quiénes fueron los agentes de estas iniciativas, no llegamos a saberlo a certeza, pero no hay duda de que las reuniones celebradas en simultáneo en las estaciones no fueron un hecho azaroso.

Hasta donde llegamos a saber, el juicio quedó estancado en tres posiciones. Llanos —que había propuesto ya un perito agrimensor- desconoció de plano a los representados de Vidal y Canal Feijoo, los últimos en llegar, presentados casi como impostores. ${ }^{55}$ En segundo lugar, el defensor de ausentes Manuel Ruiz, para quien también «el único grupo legítimo» era el de Llanos-, consideró que antes de embarcarse en la operación de mensura y división del condominio era necesario resolver primero el incidente de nulidad del juicio para luego dilucidar quiénes eran los «verdaderos condóminos». Y en este punto, apoyándose en el código de procedimientos de la provincia, diferenciaba Ruiz entre poseedores y condóminos, figuras que no necesariamente coincidían. A los poseedores que no pudieran acreditar sus derechos se les debía respetar la posesión mientras no fueran vencidos en juicio; a los condóminos que, sin vivir en Los Gallardos, se hallaran en igual situación, les cabía la justicia de menor cuantía, o sea, la de los jueces de paz. Como fuera, la clave del asunto se encontraba en determinar el derecho de cada uno de los que se presentaban como dueños.

Por último, Enrique Canal Feijoo intentó, si hemos interpretado correctamente su estrategia, redireccionar el juicio y aplazar la división. Sus representados, sostuvo, como «gente pobre que vive de su trabajo diario y del pequeñísimo producto de sus escasos bienes semovientes», no se hallaban en condiciones de pagar los ingentes gastos de una mensura. Proponía en cambio que los condóminos en pleno - y en la categoría reconocía a todos los solicitantes, sin sembrar dudas sobre la condición de nadie- nombraran una comisión que se ocupara de resolver el gran problema de «administración de la cosa común» que acechaba detrás del juicio de división. Urgía encontrar una solución para frenar la explotación clandestina de los bosques, la madre de todos los problemas. En lugar de dividir, Canal Feijoo se inclinaba por organizar de manera colectiva la gestión de los antiguos comunales por excelencia. ${ }^{56}$ Como en breve veremos, no sería la única vez que el procurador se decantara por una propuesta semejante.

55. Según Llanos, los pretendidos condóminos no presentaban «comprobantes ni dicen de donde emergen» [sus derechos], AHSDE, Mensuras de Jiménez, vol. 1, exp. 1415, f. 264. También otros pretendientes al reparto se expresaron descalificando a aquellos inoportunos y recientes listados masivos. Una tal Rita Gallardo, por ejemplo, presentaba en su solicitud una genealogía que la conectaba directamente con Andrés Gallardo. Prometía a través de su abogado combatir «a capa y espada» a quienes no fueran condóminos (f. 223). Por su parte, Telésfora de Jesús Gómez de Bracamonte apoderaba a su abogado Carlos Vella para que pudiera «reconocer condóminos y desconocer a los que, sin serlo, pretendieran tener ese carácter» (f. 210).

56. Se basaba Canal Feijoo en el Título VIII («Del condominio»), capítulo I, artículo 2699 del Código Civil («De la administración de la cosa común». Según dicho artículo, «siendo imposible por la calidad de la 
Como se dijo ya, agua y monte configuraban el piso de lo que se compartía en los campos comunes. No se trata, por supuesto, de algo novedoso ni específico de Santiago del Estero: en numerosas regiones del planeta y en todos los tiempos, dividir las superficies boscosas podía resultar poco práctico, especialmente en el marco de economías silvo pastoriles con fuerte apoyatura en las actividades de recolección. ${ }^{57}$

Por cierto, los recursos silvestres habían sido históricamente fundamentales para las poblaciones indígenas y campesinas santiagueñas. ${ }^{58}$ Incluso a fines del siglo XIX, como lo documenta Lorenzo Fazio en su Memoria descriptiva, la recogida de la algarroba mantenía una importancia tal de regular los ciclos migratorios y las actividades de subsistencia. ${ }^{59}$ Las dulces vainas de «el árbol» por antonomasia, proveían forraje para el ganado y alimento para las familias; también otros varios rubros extraídos del monte —mistol, chañar, miel, cochinilla- eran consumidos en los hogares campesinos o comercializados a escalas nada despreciables. Por lo que toca a los campos comuneros, y no obstante la información sobre la gestión de los recursos sea muy parca en nuestras fuentes, entendemos que las superficies montuosas se encontraban entre las pocas que no se hallaban sectorizadas y que resultaban de acceso libre entre los «dueños» y sus agregados. ${ }^{60}$ Aún

cosa común o por la oposición de alguno de los condóminos, el uso o goce de la cosa común o la posesión común, resolverán todos, si la cosa debe ser puesta en administración, o alquilada o arrendada». El código de 1871 está disponible en <http://www.saij.gob.ar/340-nacional-codigo-civil-lns0002653-1869-09-25/1234567890abc-defg-g35-62000scanyel\#>.

57. La connaturalidad entre los comunales y determinados ambientes — terreno inculto, bosques, zonas montañosas - es uno de los presupuestos de la historiografía sobre el tema, que es inmensa. Nos limitamos a señalar unos pocos artículos de los existentes para la península ibérica, que han inspirado nuestro trabajo. Iriarte Goñi, Iñaki: «La pervivencia de los bienes comunales y la teoría de los derechos de propiedad. Algunas reflexiones desde el caso navarro. 1855-1935», Historia Agraria, núm. 15, Murcia, 1998, pp. 113-142; Moreno Fernández, José: «El régimen comunal y la reproducción de la comunidad campesina en las sierras de La Rioja, siglos XVIII-XIX», Historia Agraria, núm. 18, Murcia, 1998, pp. 75-111 y «El comunal imaginado. De la transición en los usos de la propiedad comunal en el siglo xx, Güejar Sierra, Granada, Historia Agraria, núm. 58, Murcia, 2012, pp. 73-112. Acercándonos a nuestro presente y a la provincia de nuestro interés, es la asociación con el monte lo que hace posible la agricultura familiar, que sigue teniendo un rol de preeminencia. Ver Paz, Raúl, «Estructura agraria...», cit.

58. Farberman, Judith, «Recolección, economía campesina y representaciones de los montaraces en Santiago del Estero, siglos XVI a XIX», Prohistoria, núm. 10, Rosario, 2006, pp. 11-26; Palomeque, Silvia, «Los esteros...», cit.

59. Fazio, Lorenzo, Memoria descriptiva de Santiago del Estero, Buenos Aires, Compañía Sudamericana de Billetes de Banco, 1889, p. 107.

60. Estudios etnográficos realizados en distintas localidades de la provincia han corroborado la permanencia de esta organización de los espacios productivos. Resalto entre ellos la experiencia de los «encierros comunitarios», en los departamentos de Moreno y Figueroa y la de la Reserva Campesina de Ambargasta analizadas en Gómez Herrera, Andrea; Villalba, Ana y Jacqueline Tort, «Comunalidades en el espacio rural, una mirada desde las prácticas. Experiencias de encierros comunitarios y ganaderos en Santiago del Estero» y Días Habra, María del Huerto y Cristian Jara «La construcción de un espacio protegido mediante el contracercamiento de los bienes comunes. El diseño de la Reserva Campesina en las Serranías de Ambargasta». Ambos artículos en Paz, Raúl; Ramiro Rodríguez Sperat y Cristiana Jara (coords.), Sistemas...cit., pp. 181-232 y 233264 respectivamente. 
más: en sentido estricto, y aunque no la hemos encontrado en los documentos santiagueños, la expresión «campo común» connotaba fundamentalmente los bosques, fuente de recursos complementarios e indispensables de las economías domésticas. ${ }^{61}$

Previsiblemente, la valorización mercantil de la madera y la leña cambió de manera radical los ambientes, la economía, las costumbres y la historia de los santiagueños. Aunque saludada con optimismo a principios del siglo XX ( «iHachas cantad!», había exclamado Ricardo Rojas), la explotación forestal no había tardado en mostrar su faz oscura y tenebrosa. Orestes Di Lullo y Bernardo Canal Feijoo se encontraron entre quienes la denunciaron en El bosque sin leyenda y La estructura mediterránea argentina ${ }^{62}$ respectivamente. En efecto, a pesar de sus evidentes desencuentros ideológicos, Di Lullo y Canal coincidían en que el obraje y el ferrocarril representaban la demostración palmaria de la modernización trunca y extraviada de la provincia. Así como no existía una verdadera industria, tampoco cumplían los ferrocarriles con su objetivo de comunicar y sólo servían a intereses ajenos. Las grandes víctimas del desacierto eran las familias campesinas, desestructuradas por las migraciones y los falsos oropeles del jornal ofrecido al hachero. El obraje, por tanto, venía a herir el corazón del orden anterior. ${ }^{63}$

Muchos años después, desde posturas revisionistas, Luis Alén Lascano y Raúl Dargoltz seguían sosteniendo en lo sustancial estas argumentaciones. Expansión ferroviaria y obrajera se anudaban y levantaban una frontera imaginaria entre un pasado próspero y otro desolador, determinante del presente y del futuro de la provincia. Quizás la novedad respecto de las visiones anteriores residía en la insistencia sobre la extranjerización de los intereses a los que obrajes y ferrocarriles servían. ${ }^{64}$

Un artículo de Noemí Girbal de 1982 habilitó una lectura menos impresionista de la historia forestal santiagueña. ${ }^{65}$ En principio, la autora filiaba su despegue en una coyuntura crítica que excedía la provincia y que ataba la suerte de aquélla a la de Tucumán, su histórica rival. Si la primera mitad de la década de 1890 había sido francamente perjudicial para la ganadería y los incipientes ingenios azucareros santiagueños - en los que las élites locales habían cifrado desmesuradas esperanzas- el segundo quinquenio terminó por liquidar las opciones de inserción en mercados más amplios. En efecto, en 1895, una

61. En Los Llanos de la Rioja encontramos transacciones de mediados del siglo XIX que involucran agua, rastrojos y «campo común». Ver Boixadós Roxana y Judith Farberman, El país indiviso...cit.

62. Di Lullo, Orestes, El bosque..., cit. y Canal Feijoo, Bernardo, De la estructura mediterránea argentina, Santiago del Estero, ed. de autor, 1948.

63. Nos ocupamos puntualmente de esta cuestión en Farberman, Judith, «Tres miradas sobre paisaje, identidad regional y cultura folclórica en Santiago del Estero», Prismas. Revista de historia intelectual, núm. 14, Bernal, 2010, pp. 71-93.

64. Alén Lescano, Luis, El obraje, Buenos Aires, Centro Editor de América Latina, 1972; Dargoltz, Raúl, Hacha y quebracho. Santiago del Estero: el drama de una provincia. Buenos Aires, Castañeda, 1980.Una síntesis crítica de esta historiografía en Tasso, Alberto, Ferrocarril..., cit., pp. 179-196.

65. Girbal, Noemí, «Explotación forestal en Santiago del Estero (1895-1914). Producción, mercados, capitales invertidos. Su relación con la industria azucarera tucumana». IV Jornadas de Historia Económica Argentina, Río Cuarto, Asociación Argentina de Historia Económica y Facultad de Ciencias Económicas de la Universidad Nacional de Río Cuarto, 1982, pp. 173-214. 
crisis de superproducción de azúcar tucumana obturó cualquier intento posterior de cultivar caña en Santiago. Incluso la economía finquera de la zona de riego del Dulce, estudiada por Hebe Vessuri y Alberto Tasso, fue un fenómeno importante pero modesto - y en parte complementario- al de la explotación forestal, que aseguraba cuantiosos recursos al erario público.66

En este contexto, la legislación provincial — que permitió la entrega de inmensas superficies de tierras fiscales con montes vírgenes desde mediados del siglo XIX- y la llegada de inversores a las zonas limítrofes con el Chaco santafesino posibilitaron la expansión simultánea del obraje y del ferrocarril. ${ }^{67}$ El tendido del Ferrocarril Central Norte, ramal que corría paralelo al río Salado entre las estaciones de Fortín Inca y Ojo de Agua, nació para satisfacer las necesidades de la región devenida en forestal por excelencia y que se convirtió en el foco del obraje. Sin embargo, también el Ferrocarril Central Argentino, que en Santiago del Estero acompañaba aproximadamente el curso del río Dulce, colaboró enormemente con la producción de madera y leña. Como demostró Girbal en su momento, «la industria azucarera no puede llamarse solamente tucumana» ya que «la tercera parte de la población santiagueña estaba ocupada en esta tarea de los obrajes leñeros» y los ingenios precisaban de la leña de la provincia limítrofe para quemar el bagazo. ${ }^{68}$ En sintonía con esta interpretación, también Alberto Tasso sugirió una relación de complementariedad entre agricultura, ganadería y explotación forestal —esta vez en referencia a actividades desarrolladas dentro de la provincia-. Siguiendo las cargas de productos forestales en 22 estaciones para el período 1900 y 1935, concluyó que «los mayores volúmenes de productos forestales fueron cargados en la región del río Dulce» y que «la región nordeste, considerada habitualmente como la región forestal por excelencia, tiene primacía sólo en el rubro maderas desde 1910 y volúmenes importantes de leña en 1920 y $1935 » .{ }^{69}$

De esta escueta reseña historiográfica nos interesa recuperar tres cuestiones que hacen a la comprensión del proceso divisorio de condominios de nuestra zona: la ampliación de la región tradicionalmente atribuida a la explotación forestal a los departamentos del Dulce, la vinculación de la actividad con la economía azucarera tucumana y la incidencia del Ferrocarril Central Argentino en la destrucción de los bosques de Jiménez Segundo. Entendemos que estos datos permiten evaluar el alcance de la reconversión productiva de los bosques comunales, otrora territorios de recolección y pastura.

Ya anticipamos que la «explotación clandestina de bosques» realizada por un grupo de poseedores (no sabemos si por cuenta propia o a las órdenes de personajes más poderosos) llevó a la apertura de incidentes paralelos al juicio de división. Por lo menos tres de los representantes legales de los condóminos denunciaron a los hacheros por nombre

66. Tasso, Alberto, Ferrocarril..., cit.; Vessuri, Hebe, Igualdad..., cit., cap. 2, pp. 67-84.

67. Ver Rossi, Cecilia, «La formación del mercado de tierras en Santiago del Estero, 1850-1875. Una aproximación a la problemática», Disponible en <https://www.academia.edu/31019915>, consulta 30/4/2019.

68. Girbal, Noemí, «Explotación forestal..., cit., p. 204.

69. Tasso, Alberto, Ferrocarril..., cit., p. 212. 
y apellido. También los jueces de paz de tres distritos fueron acusados como cómplices de la depredación por dilatar el cumplimiento de los embargos ordenados sobre leñas y maderas. Los remedios propuestos, empero, fueron diferentes e invitan a la comparación con otros casos.

Para el defensor de ausentes Manuel Ruiz era «público y notorio que una infinidad de personas, propietarios unos y no propietarios otros, estos en mayor parte, están haciendo una explotación inicua de los bosques de la estancia Los Gallardos». ${ }^{70}$ Sin embargo, de poco habían servido «la infinidad de embargos» que, al no exigir a los depositarios «verdaderas rendiciones de cuentas», terminaban a la postre por estimular el desmonte. La crítica parecería dirigida al grupo iniciador de la división y a su representante Llanos, que había dejado en los administradores de la estancia la responsabilidad de vender por cuenta de la comunidad el producto de lo embargado. La medida cautelar que cabía adoptar según él —y que finalmente se adoptó- era la del embargo preventivo de la estancia para evitar que siguiera depreciándose.

Por su parte, Enrique Canal Feijoo aportó una vez más una propuesta alternativa. Admitiendo que «las explotaciones clandestinas solo benefician a un escaso número de los que ejercitan tal depredación de la propiedad común» y dada la pobreza de la mayor parte de los condóminos, se inclinaba por «la explotación legal de los bosques de la propiedad mediante una administración que vele por los intereses generales». En su opinión,

La oportunidad actual para usar y establecer esa medida es indiscutible si se tiene en cuenta la gran valorización que han alcanzado los productos madereros y la circunstancia de tratarse de uno de los pocos bosques que quedan en la actualidad en las proximidades de la vía finca del Central Argentino, que es la vía que ofrece más ventaja para la explotación forestal. ${ }^{71}$

El plan era que fueran los mismos condóminos los que decidieran qué hacer con los comunales mientras se resolvía la división ya que era a la administración, como surgía del Código Civil, a la que tocaba decidir qué hacer con esos bienes.

Ignoramos cuándo tuvo lugar la división y si Canal Feijoo fue escuchado. Alcanza en este artículo con recordar que no sólo en Los Gallardos se combatía (o, por el contrario, se alentaba y apañaba) la explotación de los montes desde un modelo que, quizás, se apartara del conocido de los obrajes. Si la explotación era «clandestina» es porque no había consenso suficiente respecto de una gestión de los recursos silvestres que fuera alternativa a la tradicional. De hecho, del grupo representado por Llanos, el iniciador de la

70. Los nombres de los hacheros surgen dos veces en el expediente. Los apellidos se encuentran entre los históricos de Los Gallardos —Orellana, Gómez, Días, Amaya, Bisgarra-y hemos localizado a algunos en el censo de 1895, a pesar de los 20 años transcurridos cuando se los denuncia. Por el contrario, solamente un hachero figura en los listados de condóminos de 1917. Supuestamente, habían sido los apoderados de Llanos quienes, realizando un recorrido de vigilancia, habían hallado a diez hacheros preparando la leña campana para cargarla en vagones en la estación de Chaupi Pozo. AHSDE, Mensuras de Jiménez, vol. 1, exp. 1415.

71. AHSDE, Mensuras de Jiménez, vol. 2, exp. 1415, f. 261. 
división, se destacaba que era el único que controlaba la depredación del bosque. No podemos sino especular con que los hacheros trabajaran para otros (¿jueces de paz? ¿almaceneros de ramos generales?) o que la suma de pequeños tráficos fuera la norma en estos años.

Como sostuvimos desde el inicio, entendemos que fue la reconversión productiva de los comunales — su redescubierto potencial forestal— la que empujó la división de condominios — por parte de actores de diversa envergadura — en toda la zona. Sin duda, esta reconversión favorecía a una minoría y conspiraba contra los medios de vida tradicionales de las familias. Vayan algunos breves ejemplos para sumar al de Los Gallardos. En la cercana estancia de Ojo de Agua, el mismo agrimensor Lacube fue hostigado por grupos de «protestantes» capitaneados por el mismísimo comisario principal de la sección Jiménez. Para el agrimensor, simplemente se trataba de una pantalla para «seguir robando leña y madera de un sobrante de terreno junto al de Los Días»: aunque interesada, la interpretación parece verosímil..$^{72}$ En Chañarpugio, también poco distante, algunos condóminos habían vendido fracciones del bosque a diversos interesados, entre los que descollaba nuestro familiar Napoleón Ávalos, el frustrado comprador de Los Gallardos. Canal Feijoo, representante legal de un grupo numeroso de condóminos también en este juicio, apenas si consiguió suspender la explotación hasta que se completara la ya inminente división del condominio. ${ }^{73}$ Finalmente, en El Vinalito, una vez más nuestro procurador buscó direccionar la actividad forestal en beneficio de los condóminos. ${ }^{74}$ Proponía esta vez «administrar la cosa común» como medio para sufragar los gastos de la división. El desmonte, por otra parte, facilitaría a su juicio la división por dejar «el campo en condiciones de igualdad». Y seguía

mis representados, que son la mayoría [de los condóminos, JF], desean que se nombre un administrador para que proceda a la explotación del bosque y deposite mensualmente su importante en el Banco de la Nación Argentina a la orden de SS con el fin de pagar los gastos de mensura y división y demás anexos y distribuir después el remanente entre los condóminos en la proporción que les corresponda.

Aunque pensado en beneficio de los menos pudientes entre los compartes, la solución del procurador no dejaba de ser paradojal. A sabiendas de la fragilidad de la figura del condominio, ataba su fin a la liquidación de los comunales.

72. AHSDE, Tribunales, vol. 254, exp. 5, 1896, s/f. Analizamos este caso en Farberman, Judith, «Agregados...», cit.

73. AHSDE, Mensuras de Jiménez, vol. 4, Paz, Pío José y compartes. Mensura, deslinde, amojonamiento y división de Chañar Pugio. 1916.

74. AHSDE, Mensuras de Jiménez, vol. 4, Cardoso, Miguel Antonio. Mensura, deslinde, amojonamiento y división de El Vinalito. 1920. 


\section{Epílogo}

Buena parte de los expedientes de mensura conservados en el Archivo Histórico de Santiago del Estero — los hay hasta 1930, aproximadamente— remiten a la división de condominios. En diferentes departamentos y desde fines del siglo XIX, promovidos por grupos mejor posicionados de «dueños históricos» o de compradores recientes y masivos de derechos y acciones, se alentó la disolución de antiguas formas colectivas de poseer. Nuevos instrumentos legales y demandas mercantiles también nuevas colaboraron con las presiones «modernizadoras» generando desposesión en las familias campesinas.

Ahora bien, el condominio era, básicamente, una figura jurídica transicional consagrada por el Código Civil y no, estrictamente, un «modo de poseer». De esta suerte, la categoría sirvió para encubrir formas que habían conocido orígenes diversos y quizás formas también diversas de gestionar lo común. Los pueblos de indios cordobeses, por ejemplo, habían sido asimilados a condominios cuando se los quiso disolver: las comunidades detrás de estos condominios eran de naturaleza diferente a las estudiadas en este artículo. ${ }^{75}$ Detrás de los llamados condominios, y también de los campos comuneros, podían esconderse formas campesinas de producción y otras que no lo eran, como creemos vislumbrar en la sierra santiagueña. De lo que se desprende que no podemos dar por sentado que ser comunero en el siglo XVIII fuera lo mismo que a fines del XIX. En rigor, la identidad entre los dueños del «terruño con apellido» parece haberse resentido con la multiplicación de sus miembros y de las poblaciones que fueron conformando. En este sentido, las tensiones visibles en Los Gallardos —y las divisiones entre grupos de condóminos en las que se manifestaron - no parecen haber sido excepcionales: es notable que los dos grupos más numerosos fueran también los menos reconocidos como parte de la membresía histórica, los supuestos impostores.

De todos modos, más allá de lo tortuoso de los trámites de división, la propiedad colectiva fue desapareciendo en los departamentos del río Dulce: la valorización de las tierras de regadío y de los bosques terminaron ganando la batalla. La misma estancia de Los Gallardos fue finalmente dividida en 9 vastos lotes, como puede observarse en un mapa catastral publicado en $1981 .^{76}$ En contraste, en ciertos sectores serranos de la provincia, los condominios mantuvieron su preeminencia hasta hoy día aunque, una vez más, la categoría jurídica pueda encubrir mucho más de lo que muestra.

Sin embargo, la liquidación de la propiedad colectiva no implicó ni la victoria de las formas codificadas de poseer ni mucho menos el destierro definitivo de las prácticas colectivas que se le asociaban. En definitiva, entendemos que el campo común había sido

75. Ver Tell, Sonia, «¿Quiénes son los comuneros? Formación de padrones y división de tierras de las comunidades indígenas en Córdoba, Argentina.1880-1900». Estudios sociales del NOA, 14, Tilcara, 2014, pp. 87-108; Cacciavillani, Pamela, «De comuneros a propietarios: reflexiones sobre los éxitos y los fracasos del proyecto liberal cordobés a finales del siglo XIX», II Encuentro Peruano Alemán, Derecho y alteridad. Lima, 2017.

76. Basualdo, Mario Angel, Rasgos..., cit., tomo I, Mapa del departamento Banda, sin foliar. 
una expresión, quizás entre las más conspicuas, de algo mucho más amplio y sentido, que excedía las formas poseer para configurar una cultura y una identidad que todavía hoy pueden reconocerse. En efecto, como es posible comprobar en un estudio reciente, las matrices comunales siguen siendo muy fuertes en una provincia todavía muy marcada por la ruralidad. En este sentido, las llamadas «explotaciones sin límites definidos» — casi la mitad de las registradas por el Censo Nacional Agropecuario de 2002 para Santiago del Estero- suelen encontrarse en el interior de campos comuneros o que reúnen características que los recuerdan poderosamente. Las zonas en las que predomina la hoy llamada «agricultura familiar», incluso los procesos de recampesinización que tuvieron lugar con posterioridad a la destrucción obrajera, han tenido mejores oportunidades de realizarse allí donde el monte proporciona forrajes y productos de recolección. La revitalización de experiencias como los «encierros comunitarios» o las «reservas campesinas», hoy estudiados a través del trabajo etnográfico y brevemente reseñadas en nota, resulta menos sorprendente habida cuenta de la larga tradición de comunalidad, resignificada cada vez en función de las nuevas condiciones y conflictos.

\section{Fuentes}

AHSDE (Archivo Histórico de Santiago del Estero), Mensuras de Jimenez 2. vol. 1. expediente 1415.

AHSDE, Tribunales, Leg. 4, expediente 53. 1826.

AHSDE, Tribunales, Leg. 19 bis, expediente 106, 1837.

AHSDE, Tribunales, Leg. 20, expediente 40. 1838.

AHSDE, Tribunales, Leg. 2, expediente 65, 1811.

AHSDE, Mensuras de Jiménez, vol. 1, expediente 183, s/f.

AHSDE, Mensuras, de Quebrachos, vol. 2, expediente 19, 1894.

AHSDE, Mensuras de Jiménez, vol. 3, expediente 5, 1929.

AHSDE, Mensuras de Jiménez, vol. 1, expediente 183, 1889.

AHSDE, Tribunales, Leg. 186, expediente 9. 1888.

AHSDE, Tribunales, Leg.254, expediente 5, 1896.

AHSDE, Mensuras de Jiménez, vol. 5, expediente 29, 1916.

AHSDE, Mensuras de Jiménez, Vol, 4, sin numerar, 1920.

AGN (Archivo General de la Nación, Buenos Aires), Censo Económico Social de 1895. Legajos 242 y 243 .

\section{Bibliografía}

Alén Lescano, Luis, El obraje, Buenos Aires, Centro Editor de América Latina, 1972.

—, Historia de Santiago del Estero, Buenos Aires, Plus Ultra, 1996.

Basualdo, Mario, Rasgos fundamentales de los departamentos de Santiago del Estero. Un documento para su historia, Santiago del Estero, 1981. Dos volúmenes. 
Boixadós Roxana y Judith Farberman, El país indiviso. Poblamiento, conflictos por la tierra y mestizajes en Los Llanos de La Rioja durante la colonia, Buenos Aires, Prometeo, en prensa.

Cacciavillani, Pamela, «De comuneros a propietarios: reflexiones sobre los éxitos y los fracasos del proyecto liberal cordobés a finales del siglo XIX», II Encuentro Peruano Alemán, Derecho y alteridad. Lima, 2017.

—, De propiedad comunal a propiedad individual. El régimen jurídico de la propiedad en Córdoba 1871-1885, Tesis de doctorado, Facultad de Derecho, Universidad Nacional de Córdoba, 2018 .

Cacciavillani, Pamela y Judith Farberman, «Nacido para morir: reflexiones en torno al uso del término condominio en el contexto de los campos comunes», inédito, 2019.

Canal Feijoo, Bernardo, De la estructura mediterránea argentina, Santiago del Estero, ed. de autor, 1948.

Canal Feijoo, Enrique, Manual para jueces de paz de campaña, Santiago del Estero, Talleres Gráficos de R. Ribas y Cia, 1909.

Dargoltz, Raúl, Hacha y quebracho. Santiago del Estero: el drama de una provincia, Buenos Aires, Castañeda, 1980.

Di Lullo, Orestes, El bosque sin leyenda. Ensayo Económico Social. Santiago del Estero, Tipografía Arcuri Caro,1937.

Días Habra, María del Huerto y Cristian Jara «La construcción de un espacio protegido mediante el contracercamiento de los bienes comunes. El diseño de la Reserva Campesina en las Serranías de Ambargasta», en Paz, Raúl; Ramiro Rodríguez Sperat y Cristiana Jara (coords.), Sistemas comunales, estructura agraria y explotaciones agropecuarias sin límites definidos: miradas alternativas, dilemas y disyuntivas, Santiago del Estero, EDIUNSE, 2018, pp. 233-264.

Escriche, Joaquín, Diccionario Razonado de Legislación y Jurisprudencia, Paris, Francia: Rosa y Bouret, 1863.

Farberman, Judith, «Familia, ciclo de vida y economía doméstica. El caso de Salavina, Santiago del Estero, en 1819», Boletín del Instituto Ravignani, núm. 12, Buenos Aires, 1996, pp. 33-59.

—, «Recolección, economía campesina y representaciones de los montaraces en Santiago del Estero, siglos XVI a XIX», Probistoria, núm. 10, Rosario, 2006, pp. 11-26.

—, «Tres miradas sobre paisaje, identidad regional y cultura folclórica en Santiago del Estero», Prismas. Revista de historia intelectual, núm. 14, Bernal, 2010, pp. 71-93.

—, «El mancomún en Santiago del Estero entre la colonia y el siglo XIX. Historia y fundamentos de un problema de investigación», Indoamérica, núm. 7, Santiago del Estero, 2016, pp. 13-36.

—, «Tierras mancomunadas en Santiago del Estero. Problemas y estudios de caso entre la colonia y el siglo XIX», Mundo Agrario, vol. 17, núm. 36, La Plata, 2016. Disponible en: <http://www. mundoagrario.unlp.edu.ar/article/view/MAe025>.

—, «Dueños, agregados, derechos de propiedad y matrices comunales en Santiago del Estero. Una aproximación histórica»; Paz, Raúl; Ramiro Rodriguez Sperat Ramiro y Cristian Jara (coords.), Sistemas comunales, estructura agraria y explotaciones agropecuarias sin límites definidos: miradas alternativas, dilemas y disyuntivas, Santiago del Estero, EDIUNSE, 2018, pp. 63-106.

-, «Los avatares de la mancomunión. Propiedad indivisa, armonías y conflictos en las costas del río Dulce. Santiago del Estero, siglos XVIII y XIX», Revista de Indias, num. 275, vol. 4, Sevilla, 2019, pp. 111-142.

Fazio, Lorenzo, Memoria descriptiva de Santiago del Estero, Buenos Aires, Compañía Sudamericana de Billetes de Banco, 1889. 
Gancedo, Alejandro, Memoria histórica y descriptiva de la provincia de Santiago del Estero. Buenos Aires, Stiller y Laas, 1885.

Garavaglia, Juan Carlos, «¿Cómo se mide la tierra? Las mensuras en el Río de la Plata, siglos XVII a XIX»; Garavaglia, Juan Carlos y Pierre Gautreau (eds.), Mensurar la tierra, controlar el territorio. América Latina, siglos XVIII y XIX, Rosario, Prohistoria, 2011, pp. 27-62.

Girbal, Noemí, «Explotación forestal en Santiago del Estero (1895-1914). Producción, mercados, capitales invertidos. Su relación con la industria azucarera tucumana». IV Jornadas de Historia Económica Argentina, Río Cuarto, Asociación Argentina de Historia Económica y Facultad de Ciencias Económicas de la Universidad Nacional de Río Cuarto, 1982, pp. 173-214.

Gómez Herrera, Andrea; Ana Villalba, y Jacqueline Tort, «Comunalidades en el espacio rural, una mirada desde las prácticas. Experiencias de encierros comunitarios y ganaderos en Santiago del Estero»; Paz, Raúl; Ramiro Rodríguez Sperat y Cristiana Jara (coords.), Sistemas comunales, estructura agraria y explotaciones agropecuarias sin limites definidos: miradas alternativas, dilemas y disyuntivas, Santiago del Estero, EDIUNSE, 2018, pp. 181-232.

Iriarte Goñi, Iñaki: «La pervivencia de los bienes comunales y la teoría de los derechos de propiedad. Algunas reflexiones desde el caso navarro. 1855-1935», Historia Agraria, núm.15, Murcia, 1998, pp. 113-142.

López, Cristina, «Tierras comunales, tierras fiscales: el tránsito del orden colonial a la revolución», Revista Andina, núm. 43, Cuzco, 2006, pp. 215-238.

Moreno Fernández, José, «El régimen comunal y la reproducción de la comunidad campesina en las sierras de La Rioja, siglos XVIII-XIX», Historia Agraria, núm. 18, Murcia, 1998, pp. 75-111.

Moreno Fernández, José, «El comunal imaginado. De la transición en los usos de la propiedad comunal en el siglo Xx, Güejar Sierra, Granada, Historia Agraria, núm. 58, Murcia, 2012 pp. 73-112.

Otero, Hernán, Estadística y nación. Una historia conceptual del pensamiento censal de la Argentina moderna, 1869-1914, Buenos Aires, Prometeo, 2006.

Palomeque, Silvia, «Los esteros de Santiago. Acceso a los recursos y participación mercantil. Santiago del Estero en la primera mitad del siglo XIX». Data. Revista del Instituto de Estudios Andinos y Amazónicos, núm. 2, La Paz, 1992, pp. 9-63.

Paz, Raúl, «Estructura agraria, explotaciones sin límites definidos y matrices comunales: miradas alternativas, dilemas y disyuntivas», en Paz, Raúl; Ramiro Rodriguez Sperat y Cristian Jara (coords.), Sistemas comunales, estructura agraria y explotaciones agropecuarias sin limites definidos: miradas alternativas, dilemas y disyuntivas, Santiago del Estero, EDIUNSE, 2018, pp. 23 62.

Peralta Puy, Héctor, «El camino del Palomar y su influencia en el poblamiento y su influencia en el poblamiento y evolución territorial del actual departamento Jiménez, provincia de Santiago del Estero, 1753-1828», disponible en: <https://unse.academia.edu/H\%C3\%A9ctorFrancisco PeraltaPuy>.

Pérez Castañeda, Juan Carlos. (2018) «Los condueñazgos en México. Siglo XIX», Signos Históricos, núm. 40, México, 2018.

Pro Ruiz, Juan, «Mensuras, catastro y construcción estatal». Introducción a Garavaglia, Juan Carlos y Pierre Gautreau (eds.), Mensurar la tierra, controlar el territorio. América Latina, siglos XVIII y XIX, Rosario, Prohistoria, 2011, pp. 13-26.

Ríos, Ricardo, «La posesión precaria agobia y destruye el espíritu. Títulos y antecedentes de la propiedad Chupilta. Original procedimiento para establecer la extensión». Revista de la Junta 
de Estudios Históricos de Santiago del Estero, vol. 3, núm. 7-10, Santiago del Estero, 1945, pp. 85-103.

Rossi, Cecilia, «La formación del mercado de tierras en Santiago del Estero, 1850-1875. Una aproximación a la problemática», inédito, $\mathrm{s} / \mathrm{f}$.

Rossi, María Cecilia y Guillermo Banzato, «Redefiniendo las fronteras y las formas de ocupación de las tierras del antiguo Copo en Santiago del Estero (desde el siglo XVI a mediados del XIX», Investigaciones y ensayos, núm. 64, 2017, pp. 29-72.

Rossi, y Juan Antonio Rízolo Burgos, «Las leyes sobre tierras públicas en Santiago del Estero. 18581862». En Banzato, Guillermo y Graciela Blanco. La cuestión de la tierra pública en Argentina: a 90 años de la obra de Miguel Ángel Cárcano, Rosario, Prohistoria Ediciones, 2009, pp. 133 162.

Tasso, Alberto, Ferrocarril, quebracho y alfalfa. Un ciclo de agricultura capitalista en Santiago del Estero, 1870-1940, Córdoba, Alción Editora, 2007.

Tell, Sonia, «¿Quiénes son los comuneros? Formación de padrones y división de tierras de las comunidades indígenas en Córdoba, Argentina.1880-1900», Estudios sociales del NOA, 14, Tilcara, 2014, pp. 87-108.

—, «¿Quiénes son los comuneros? Formación «Campos en común, campos contendidos. Apropiaciones de la comunidad en Córdoba (siglo XIX)», Revista de Ciencias Sociales, núm. 27, Bernal, 2015, pp. 67-85.

Tenti, María Mercedes, La formación de un estado periférico. Santiago del Estero (1875-1916), Santiago del Estero, Ediciones Universidad Católica de Santiago del Estero, 2013.

Teruel, Ana y Cecilia Fandos, «Procesos de privatización y desarticulación de tierras indígenas en el norte de Argentina en el siglo XIX», Revista Complutense de Historia de América, núm. 35, Madrid, 2009, pp. 233-256.

Vessuri, Hebe, Igualdad y jerarquia en Antajé, Buenos Aires, IDES-Al Margen, 2011.

Zubricki, Bernarda, «Herederos dueños y "derechosos". Propiedad y herencia de la tierra en Asampay, Argentina», Sociedades Rurales, Producción y Medio Ambiente, núm. 4, vol. 1, México, 2003, pp. 19-27. 